\title{
Electro-acupuncture alleviates motor deficits and maladaptive striatal plasticity in partial-lesioned parkinsonian mice
}

\section{Wenting Su}

Capital medical university

Jianan Yu

Capital Medical University

Min Li

Capital medical university

Ke Wang

Capital medical university

Chang Liu

Capital medical university

Jun Jia ( $\nabla$ jiajun@ccmu.edu.cn )

Capital Meedical university

Xiaomin Wang

Capital Medical University

\section{Research}

Keywords: Electro-acupuncture, Motor skills, Glutamate receptor, Striatal synaptic plasticity, Partiallesioned 6-OHDA mice

Posted Date: August 27th, 2020

DOI: https://doi.org/10.21203/rs.3.rs-64367/v1

License: (a) (1) This work is licensed under a Creative Commons Attribution 4.0 International License. Read Full License 


\section{Abstract \\ Background}

Parkinson's disease is characterized by abnormal synaptic transmission in the corticostriatal circuit that leads to deficits in motor abilities. Electro-acupuncture has shown to improve the motor behaviors in parkinsonian models. However, the potential mechanisms underlying the electro-acupuncture treatment, specifically in the partial-lesioned model, remain unclear.

\section{Methods}

By utilizing multiple approaches, including electrophysiological, immunohistochemistrical, molecular and behavioral methods, we assessed the effect of electro-acupuncture on the motor dysfunction and striatal synaptic plasticity in a partial-lesioned mouse model induced by intrastriatal injection of 6hydroxydopamine.

\section{Results}

Electro-acupuncture ameliorated the disrupted gross and fine motor skills in 6-hydroxydopamine-lesioned mice. Notably, electro-acupuncture not only restored the injured corticostriatal long-term potentiation, but also reversed the loss of GluN1-containing NMDA receptors and GluA1-containing AMPA receptors in the striatum. Furthermore, the antagonists selective for AMPA receptors and NMDA receptors blocked the effect of electro-acupuncture on the corticostriatal long-term potentiation in 6-hydroxydopamine-treated mice.

\section{Conclusions}

These data suggest that the postsynaptic glutamate receptors in the striatum undergo the maladaptive changes in the early stage of Parkinson's disease. Electro-acupuncture improves the motor skills via a mechanism involving the modulation of corticostriatal synaptic plasticity and specific glutamate receptors in a partial-lesioned rodent model.

\section{Background}

The key pathophysiologic characteristics of Parkinson's disease (PD) are the degeneration of dopaminergic neurons in the substantia nigra pars compacta (SNc) and the denervation of dopaminergic projection in the striatum [1]. Motor symptoms of PD appear after $50 \%$ of $\mathrm{SNc}$ dopaminergic neurons are degenerated [2,3] and $70 \sim 80 \%$ of nigrostriatal dopaminergic innervation is lost [1, 4]. So far, neither clinical medication such as L-3,4-dihydroxyphenylalanine nor surgical therapy such as deep brain stimulation can effectively cure or stop the development of these motor symptoms in the advanced stage 
[5]. Therefore, the optimal therapeutic strategy aims to delay the pathological deterioration and alleviate motor symptoms in the early period of PD.

The neurotoxin 6-hydroxydopamine (6-OHDA) has been used extensively to induce animal models of PD [6]. Typically, rodents develop severe movement deficiencies and damage of the nigrostriatal dopamine (DA) system after 6-OHDA injection in the medial forebrain bundle (MFB) or SNc. In addition, unilateral injection of 6-OHDA into the striatum, especially in a low dose, would induce the incomplete depletion of striatal DA [7-9]. As such, the 6-OHDA lesion in the striatum can be utilized to explore the early pathogenic events of PD. Targeting the early events is essential for the development of therapeutic interventions, although the neuroanatomical, functional, and molecular mechanisms underlying the motor disorders in the early stages of PD remain largely elusive.

Loss of dopaminergic innervation in the striatum leads to the deficits in motor skills and triggers aberrant striatal synaptic plasticity [7, 10-13]. DA depletion at different extents have been shown to differentially affect striatal synaptic plasticity, subsequently leading to PD motor symptoms of various severity $[7,14$, 15]. A complete DA denervation triggers maladaptive synaptic plasticity including loss of both long-term potentiation (LTP) and long-term depression (LTD) at corticostriatal synapses $[7,16,17]$ and induces severe motor behaviors. However, denervation in a partial lesion rat model of PD altered LTP but not LTD, accompanied by mild motor symptoms [7]. Apparently, striatal synaptic plasticity is closely linked to motor performances $[7,18]$. Intervening striatal synaptic plasticity, especially in the early stage of PD, may thus be crucial for producing significant improvement of motor symptoms.

As an alternative and complementary therapy, acupuncture or electro-acupuncture (EA) has long been used to alleviate the symptoms of patients with PD and improve their quality of life [19-21]. Our studies have consistently demonstrated that high-frequency EA stimulation $(100 \mathrm{~Hz})$ alleviated movement disorders in multiple parkinsonian models [22-25]. However, whether EA affects motor skills or striatal plasticity in the early stage of PD has not been elucidated. In the present study, we used a partial-lesioned 6-OHDA model to analyze the changes of synaptic plasticity in the early stage of DA depletion. We first investigated the effect of EA treatment on motor skills in the early stage of PD. We then examined whether the therapeutic effect of EA was based on the modulatory role of EA in striatal synaptic plasticity. Finally, we determined the biochemical targets sensitive to EA and their roles in processing the effect of EA on the aberrant striatal synaptic plasticity in partial-lesioned mice.

\section{Methods}

\subsection{Animals}

Male C57BL/6J mice, aged 6-8 weeks (body weight 20-25 g) were provided by the animal facility of Capital Medical University, Beijing, China. Mice were housed in groups of 5 mice/cage on a 12/12 h light/dark cycle and with ad libitum access to food and water throughout, except for mice during food deprivation for staircase test. All experimental procedures were approved by the Animal Ethics Committee 
of Capital Medical University and carried out in accordance with National Institutes of Health Guide for the Care and Use of Laboratory Animals. All efforts were made to reduce the number of animals to be used for the study and to minimize their suffering.

\subsection{Experimental design}

The timeline for experimental treatment is present in Fig. 1a. Briefly, mice were randomly divided into two groups: sham (saline-injection) group and 6-OHDA-lesioned group. Two weeks after 6-OHDA injection, mice were tested with apomorphine (APO) and those who performed more than 5 turns per minute were chosen as parkinsonian model mice, which were further randomly divided into two groups, named 6OHDA and 6-OHDA + EA group, respectively. During the following four weeks, the mice of 6-OHDA + EA group received EA treatment. The effect of EA on motor performance and skills were tested at 3 different time points: before EA, 2nd and 4th weeks after EA stimulation. After 4-week EA treatment, mice were sacrificed for different biological tests.

\subsection{Unilateral 6-OHDA lesion}

Mice were anaesthetized by an intraperitoneal (i.p.) injection of pentobarbital sodium $(30 \mathrm{mg} / \mathrm{kg})$ and placed into a stereotaxic apparatus (Kopf, Germany). 6-OHDA (H116, Sigma) was dissolved in normal saline containing $0.02 \%$ ascorbic acid and injected in two deposits in the striatum at the following coordinates: $\mathrm{AP}=+0.5 \mathrm{~mm}$ anterior to bregma; $\mathrm{ML}=-2.0 \mathrm{~mm}$ lateral to bregma, $\mathrm{DV}=-3.0 \mathrm{~mm}$ and then DV $=-2.0 \mathrm{~mm}$ ventral to dura. At each site, 6-OHDA $(4 \mu \mathrm{g})$ was injected in a total volume of $0.78 \mu \mathrm{l}$ $(5.14 \mu \mathrm{g} / \mu \mathrm{l})$ at a rate of $0.26 \mu \mathrm{l} / \mathrm{min}$ with a $10 \mu \mathrm{l}$ microsyringe. The microsyringe was left for additional 2 min for fully diffusion of drug before being slowly removed and the wound was cleaned and sutured. Mice in sham group underwent the same surgery protocol but received the same volume of normal saline solution containing $0.02 \%$ ascorbic acid. Animals were allowed 2 weeks for recovery before behavioral testing commenced. Animal health and behavior were monitored daily following the surgery.

\subsection{EA treatment}

EA stimulation was performed as described previously [24, 26]. In brief, hindlimbs were cleaned with $75 \%$ alcohol and then each leg was inserted two sterilized stainless-steel needles $(0.18 \mathrm{~mm}$ diameter $\times 3 \mathrm{~mm}$ length) at two acupoints: one is Zusanli (ST36, $2 \mathrm{~mm}$ lateral to the anterior tubercle of tibia) and the other is Sanyinjiao (SP6, $2 \mathrm{~mm}$ proximal to the upper border of medial malleolus, at the posterior border of the tibia) (Fig. 1b). Bidirectional square wave electrical pulses (0.2 ms duration, $100 \mathrm{~Hz})$, generated from a Han's acupoint nerve stimulator (HANS, Neuroscience Research Institute, Peking University), were connected to the stainless-steel needles in both hindlimbs simultaneously and were administered for a total of 30 min per day, 5 days per week, during which the intensity of the stimulation was stepwise increased from $1.0 \mathrm{~mA}$ to $1.2 \mathrm{~mA}$ and then to $1.4 \mathrm{~mA}$, and each step lasted for $10 \mathrm{~min}$. The duration of EA treatment was limited to 4 weeks. To evaluate the neuronal activation in the striatum for the acute EA stimulation, c-fos expression was detected after sham or model mice received an acute 30-min EA treatment. Following a 90 min recovery period, mice were sacrificed for histological detection. 


\subsection{Behavioral tests}

\subsubsection{Apomorphine-induced rotation}

Two weeks after surgery, mice were individually placed in cylinders with the diameter of $90 \mathrm{~mm}$ and height of $120 \mathrm{~mm}$, in a closed room to avoid any environmental disturbance, and allowed to habituate for $5 \mathrm{~min}$ before APO ( $0.05 \mathrm{mg} / \mathrm{kg}$, Sigma) injection. APO dissolved in normal saline containing $0.02 \%$ ascorbic acid was delivered i.p.. Mice were monitored for $30 \mathrm{~min}$, during which the highest 3 consecutive minutes of contralateral minus ipsilateral rotations were used for analysis. Mice with the net number of contralateral rotations $>5$ turns/min were validated as successful model.

\subsubsection{Rotarod}

Before the surgery, all mice were trained on rotarod (Ugo Basil, Italy) for five consecutive days, in order to reach a stable performance on the constant and accelerating rod. On the test day, mice were placed on the rotarod with an initial rotation speed at 4 rotations/min (rpm), which was accelerated to $60 \mathrm{rpm}$ within $5 \mathrm{~min}$. The time taken to fall was automatically recorded when mice landing on the base of the apparatus. Each mouse was given three trials and the averaged latency time was recorded.

\subsubsection{Open field test}

Mice were placed individually in the center of an open-field arena $(50 \times 50 \mathrm{~cm})$. The behaviors of the mice were recorded using a CCD camera positioned above the cage for $30 \mathrm{~min}$. The total movement distance was recorded and analyzed simultaneously (SuperMaze, Shanghai Xinruan). All experiments were performed during 9:00 am to 16:00 pm. The environment was kept dark and quiet during the entire procedure. The apparatus was carefully cleaned with $75 \%$ alcohol and water between each trail.

\subsubsection{Staircase test}

Staircase apparatus (Campden Instruments, UK) was used to measure the coordinated grasping skill in mice following unilateral lesions. As described previously [27], mice were encountered a $20 \mathrm{~h}$ food deprivation regime during the training and testing period to increase their motivation to retrieve the pellets. They were given food access for $4 \mathrm{~h}$ daily immediately after each session. Mice were first familiarized with the food pellets by placing approximately 50 into each home cage on three consecutive days. They were then familiarized to the test box by placing food pellets along the surface of the central trough as well as on the staircase steps for a further day. On the subsequent three days, the double staircase was baited with two pellets per step, i.e. 16 on each side of 8 steps and the mouse was placed in the start compartment. Each session lasted for 15 min daily and only the 3rd day was considered for measurement. At the end of each session, the number of pellets retrieved (16 minus pellets remained) in 15 min were counted on both sides.

\subsection{Immunohistochemistry}


After the four-week EA treatment, mice were deeply anaesthetized with pentobarbital sodium $(30 \mathrm{mg} / \mathrm{kg})$ and intracardially perfused with $0.9 \%$ sodium saline followed by ice-cold $4 \%$ paraformaldehyde (PFA). Brains were removed, post-fixed in 4\% PFA for $24 \mathrm{~h}$ and then transferred to $20 \%$ and $30 \%$ sucrose in PBS for tissue cryoprotection, consecutively. Coronal sections were cryosectioned at $40 \mu \mathrm{m}$ thickness. Sections were collected and stored at $4{ }^{\circ} \mathrm{C}$ in an antifreeze solution.

For immunohistochemistry, free-floating sections were rinsed with $0.01 \mathrm{M}$ PBS before incubated with $0.3 \%$ Triton X-100. Endogenous peroxidase activity was then quenched with $3 \% \mathrm{H}_{2} \mathrm{O}_{2}$. After washing, sections were blocked in normal horse serum obtained from ABC-peroxidase kit (PK-4002, Vector Laboratories). They were then incubated with anti-tyrosine hydroxylase antibody ( $T H, 1: 2000$, SAB4200699, Sigma) or anti-c-Fos antibody (1:1000, ABE457, Millipore) diluted in the same blocking solution as described above, overnight at $4{ }^{\circ} \mathrm{C}$. Sections were then incubated with biotinylated anti-mouse secondary antibody, before treated with avidin-biotin peroxidase complex reagent from the $A B C$-peroxidase kit. Following washing, the reaction product was developed using 3,3'-diaminobenzadine (DAB kit, Zhongshan Golden Bridge, China). Tissue sections were mounted, dehydrated in graded ethanol dilutions, cleared in xylene and cover slipped with mounting medium.

Slices collected after patch-clamp recordings were fixed with $4 \%$ PFA overnight in $4{ }^{\circ} \mathrm{C}$ and stained with Alexa Fluor-488-conjugated avidin (A21370, Invitrogen). The z-stack images of individual cells $(0.5 \mu \mathrm{m}$ between successive images) and 3-4 dendrites per cell ( $0.3 \mu \mathrm{m}$ between successive images) were acquired by a confocal microscope (Leica SP8, Germany) equipped with a $63 \times$ objective. Threedimension reconstruction of the cells was performed using Imaris 8.0 (Bitplane, Switzerland) to form a continuous 3D representation of the entire cell structure.

\subsection{Histological quantification}

A total of 4-6 consecutive sections were selected from each brain to examine TH immunoreactive cells in $\mathrm{SNc}$ and TH positive fibers in the striatum. Unbiased stereology was used to estimate the number of dopaminergic neurons of each section under a $20 \times$ objective with Stereo Investigator software (MBF Bioscience, USA). The relative remained number of $\mathrm{TH}$ neurons was calculated as a ratio of the number of the lesioned side relative to the unlesioned side. Images of TH-stained striatal sections were obtained by light microscope (Olympus BX51, Japan). Immunoreactive optical densities of TH positive fibers in the striatum were calculated using Image-Pro Plus 6.0 (Media Cybernetics, USA). 3-4 mice from each group were used for quantification. Additionally, consecutive sections stained for c-fos of each mouse were scanned with Pannoramic scan (3DHISTECH, Hungary). In the ipsilateral dorsolateral striatum, the number of c-fos positive cells were counted in a $0.5 \mathrm{~mm} \times 0.5 \mathrm{~mm}$ region of interest using Image-Pro Plus 6.0 (Media Cybernetics, USA). The c-Fos counts of each mouse were represented by average counting per section.

\subsection{High performance liquid chromatography (HPLC)}

Tissue levels of DA and Glutamate were determined as previously reported [28]. The striatum was rapidly dissected, frozen in liquid nitrogen, and stored at $-80^{\circ} \mathrm{C}$. Striatal tissue was weighed and homogenized in 
$200 \mu \mathrm{l}$ perchloric acid $(0.4 \mathrm{M})$. Homogenates were centrifuged for $20 \mathrm{~min}$ at $12,000 \mathrm{rpm}$ at $4{ }^{\circ} \mathrm{C}$ after icebath for $60 \mathrm{~min}$. Supernatant was mixed with mobile phase solution and was kept from light for 60 -minice-bath, followed by centrifugation for $20 \mathrm{~min}$ at $12,000 \mathrm{rpm}$ at $4{ }^{\circ} \mathrm{C}$. The resultant supernatant was filtered with a $0.22 \mathrm{~mm}$ membrane. The content of DA was detected by injecting an aliquot of the resulting solution into the HPLC-ECD pump (CoulArray, USA) with four potentials of -150, 100, 220 and $400 \mathrm{mV}$ and flow rate at $1 \mathrm{ml} / \mathrm{min}$. Chromatographic separation was performed using a HR-C18 reversephase column $(80 \times 4.6 \mathrm{~mm}$ I.D., $3 \mu \mathrm{m}, 100 \mathrm{~A}$, ESA Inc., USA). The mobile phase $(\mathrm{pH}=4.3)$ contains $63.5 \mathrm{mM}$ citric acid monohydrate, $60.9 \mathrm{mM}$ trisodium citrate dihydrate, $0.1 \mathrm{mM}$ EDTA, $0.5 \mathrm{mM} 1$ octanesulfonic acid sodium salt, and $8 \%$ methanol. The glutamate quantification was later carried out in the HPLC-electrochemiluminescence system. Each concentration was adjusted with respect to the standard and quantified from a standard curve.

\subsection{Whole-cell patch-clamp electrophysiology}

Four weeks following EA stimulation, mice were anesthetized with pentobarbital sodium $(30 \mathrm{mg} / \mathrm{kg})$ and transcardially perfused with ice cold, bubbling $\left(95 \% \mathrm{O}_{2} / 5 \% \mathrm{CO}_{2}\right)$ sucrose slicing solution containing (in $\mathrm{mM}$ ) sucrose 213, glucose 10, $\mathrm{KCl} 2.5, \mathrm{NaH}_{2} \mathrm{PO}_{4} 1.25, \mathrm{NaHCO}_{3} 26, \mathrm{CaCl}_{2}$ 0.2, $\mathrm{MgSO}_{4}$ 5. Tissue blocks from mice were cut coronally $(250 \mu \mathrm{m})$ on a vibratome (Leica VT1200S, Germany) through the striatum in ice cold, bubbling sucrose slicing solution. Slices were then transferred to a holding chamber consisting of holding solution containing (in $\mathrm{mM}$ ) $\mathrm{NaCl} 125$, glucose $10, \mathrm{KCl} 2.5, \mathrm{NaH}_{2} \mathrm{PO}_{4} 1.25, \mathrm{NaHCO}_{3} 26, \mathrm{CaCl}_{2} 1$, $\mathrm{MgSO}_{4} 5$ at $34{ }^{\circ} \mathrm{C}$. After 40-min recovery, slices were kept for at least $30 \mathrm{~min}$ in the room temperature (RT) before recording. Whole-cell patch clamp recordings were obtained from striatal MSNs in oxygenated artificial cerebrospinal fluid (ACSF) composed of (in $\mathrm{mM}$ ) $\mathrm{NaCl} 125$, glucose 10, $\mathrm{KCl} 2.5, \mathrm{NaH}_{2} \mathrm{PO}_{4} 1.25$, $\mathrm{NaHCO}_{3} 26, \mathrm{CaCl}_{2} 2.6, \mathrm{MgSO}_{4} 1.3$ in RT. MSNs of the dorsolateral striatum were identified visually by infrared microscopy (Scientifica, UK) and by their electrophysiological properties. For mEPSCs studies, internal solution composed of (in mM) K-D-gluconate 140, $\mathrm{KCl} 3, \mathrm{MgCl}_{2} 2$ 2, HEPES 10, EGTA 0.2, Na-ATP 2 was used. $0.2 \%(\mathrm{w} / \mathrm{v})$ biocytin was also added for post hoc avidin staining. Picrotoxin $(50 \mu \mathrm{M})$ were bath applied to block fast GABAAR transmission, and TTX $(0.5 \mu \mathrm{M})$ were added to prevent action potential firing. The cells were held at $-70 \mathrm{mV}$ for continuous recordings for $5 \mathrm{~min}$. Data were analyzed in Minianalysis (synaptosoft, USA) for frequency and amplitude of miniature events. For paired-pulse ratio and AMPA/NMDA ratio analysis, intracellular solution containing (in $\mathrm{mM}$ ) $\mathrm{CsMeSO}_{3} 120, \mathrm{NaCl} 5$, TEA-Cl 10, HEPES 10, QX-314 5, EGTA 0.1, Mg-ATP 4, Na-GTP 0.3, pH 7.4 was used. Glutamatergic EPSCs were evoked by a stimulating bipolar electrode (FHC, USA) placed on the corpus callosum between the cortex and the dorsal striatum. AMPA and NMDA currents were measured at $-70 \mathrm{mV}$ and $+40 \mathrm{mV}$, respectively. 10 sweeps were recorded at both holding potentials separated by time intervals of $15 \mathrm{~s}$. The traces were analyzed and averaged offline using Patchmater (HEKA, Germany). The current peak at $+70 \mathrm{mV}$ was extracted as the AMPA component and the decay of the AMPA current was used to establish the time window for the measurement of the NMDA component. A 10 ms time window starting $50 \mathrm{~ms}$ after the stimulation was used at $+40 \mathrm{mV}$ to measure the NMDA current. Recordings were amplified and digitized (20 kHz) using HEKA EPC 10 USB. Patch pipettes were pulled with a micropipette puller (Narishige PC-10, 
Japan) and had initial resistances of 6-8 $\mathrm{M} \Omega$ for current clamp and 4-6 $\mathrm{M} \Omega$ for voltage clamp experiments. Liquid junction potential was not corrected during the experiment. Recordings were performed with pipette capacitance and access resistance compensated throughout the experiment. Data were discarded when access resistance increased beyond $30 \mathrm{M} \Omega$.

\subsection{Extracellular multichannel electrophysiology}

The process of preparing acute brain slices were similar to those described previously [29, 30]. Mice were sacrificed by decapitation after anesthesia with pentobarbital sodium $(30 \mathrm{mg} / \mathrm{kg})$. Subsequently, the whole brain was rapidly removed and immediately soaked in NMDG cutting solution containing (in $\mathrm{mM}$ ) NMDG 92, $\mathrm{KCl} 2.5, \mathrm{NaH}_{2} \mathrm{PO}_{4} 1.25, \mathrm{NaHCO}_{3} 30$, HEPES 20, glucose 25, thiourea 2, Na-ascorbate 5, Napyruvate $3, \mathrm{CaCl}_{2} 0.5$ and $\mathrm{MgSO}_{4} 10$. With the portions containing the midbrain and cerebellum being trimmed, the remaining brain block containing the striatum was placed on the ice-cold stage of a vibrating tissue slicer (Dosaka, DTK-1000, Japan). The stage was immediately filled with oxygenated NMDG cutting solution. The thickness of each tissue slice was set at $300 \mu \mathrm{m}$. Each slice was gently transferred with a homemade pipet into a holding chamber containing oxygenated NMDG cutting solution, allowing the initial protective recovery to proceed for $12 \mathrm{~min}$ at $32-34{ }^{\circ} \mathrm{C}$. After the initial recovery period, the slices were transferred into another holding chamber containing room-temperature HEPES holding solution consist of (in $\mathrm{mM}$ ) NaCl 92, $\mathrm{KCl} 2.5, \mathrm{NaH}_{2} \mathrm{PO}_{4} 1.25, \mathrm{NaHCO}_{3} 30, \mathrm{HEPES} 20$, glucose 25, thiourea 2, Na-ascorbate 5, Na-pyruvate $3, \mathrm{CaCl}_{2} 2$ and $\mathrm{MgSO}_{4} 2$ until transferred to recording dish contained ACSF consist of (in $\mathrm{mM}$ ) $\mathrm{NaCl} 119, \mathrm{KCl} 2.5, \mathrm{NaH}_{2} \mathrm{PO}_{4} 1.25, \mathrm{NaHCO}_{3} 24$, glucose 12.5, $\mathrm{CaCl}_{2} 2$ and $\mathrm{MgSO}_{4} 2$. $\mathrm{Mg}^{2+}$-free ACSF was prepared for LTP recording procedures.

Recordings were carried out in a multielectrode dish (Panasonic, MED 64 planar microelectrodes). After a 15-min adaptation of the slice, one of the 64 available planar microelectrodes (located in the corpus callosum), which produced the highest amplitude was selected for stimulation. Field potentials evoked at the remaining sites (located in the dorsolateral striatum) were amplified by the 64-channel main amplifier and then digitized at a $20 \mathrm{kHz}$ sampling rate. An input-output curve was first determined for each slice via the measurements of fEPSP amplitude in response to a series of stimulation intensities starting at $10 \mu \mathrm{A}$. The intensity of the test stimulus was then adjusted to elicit $30-50 \%$ of the maximum amplitude. A baseline was then recorded for additional 15 minutes once every 1 minute. High-frequency stimulation (HFS) consisted of three bursts, each containing four pulses at $100 \mathrm{~Hz}$ with an inter-burst interval of $200 \mathrm{~ms}(3 \times 3 \mathrm{HFS})$, both LTD and LTP were induced by HFS except $\mathrm{Mg}^{2+}$ was omitted from the ACSF when induced LTP [31, 32]. After $3 \times 3 \mathrm{HFS}$, the test stimulus was repeatedly delivered for $2 \mathrm{~h}$ for observations of any changes in LTP or LTD magnitude. Traces were obtained and analyzed using Mobius (Alpha Med Science Inc, Osaka, Japan). 6-Cyano-7-nitroquinoxaline-2,3-dione (CNQX, $2 \mu \mathrm{M}$, Sigma), (s)-aAmino-3-hydroxy-5-methylisoxazole-4-propionic acid ((s)-AMPA, $10 \mu \mathrm{M}$, Sigma), 5,7-Dichlorokynurenic acid (DCKA, $10 \mu \mathrm{M}$, Sigma), glycine (150 $\mu \mathrm{M}$, Sigma) were bath applied to slices of separate groups to observe their roles on plasticity of the striatum. 


\subsection{Western blot analysis}

After anesthesia, mice were sacrificed and brains were removed. The tissue of the striatum was dissected and frozen in liquid nitrogen immediately. The tissue was lysed in ice-cold TEVP buffer composed of (in $\mathrm{mM}$ ) sucrose 320, Tris- $\mathrm{HCl} 10$ ( $\mathrm{pH}=7.4$ ), $\mathrm{NaF} 5, \mathrm{Na}_{3} \mathrm{VO}_{4} 1$, EDTA 1, and EGTA 1, containing protease inhibitors cocktail. Protein concentrations were determined by Bradford Protein Assay Kit (Thermo Fisher Scientific, USA). A total of $10 \mu \mathrm{g}$ proteins were loaded on a $10 \%$ SDS-PAGE gel. Proteins were transferred to nitrocellulose membranes which were incubated with a primary antibody overnight at $4{ }^{\circ} \mathrm{C}$. Primary antibodies include rabbit anti-GluA1 antibody (1:2000, ab109450, abcam), rabbit anti-GluA2 antibody (1:2000, ab206293, abcam), mouse anti- $\beta$-Actin antibody (1:3000, A3854, Sigma), rabbit anti-GluN1 antibody (1:1000, ab109182, abcam), rabbit anti-GluN2A antibody (1:200, ab124913, abcam), rabbit antiGluN2B antibody (1:1000, ab65783, abcam). Secondary antibodies include IRDye 680-conjugated goat anti-rabbit IgG (LI-COR Biosciences, USA) and IRDye 800-conjugated goat anti-mouse antibody. Immunoreactive bands were visualized using Odyssey imaging system (LI-COR Biosciences). Optical densities of protein bands were normalized to the density of actin bands visualized on the same membrane.

\subsection{2. $\mathrm{qRT}-\mathrm{PCR}$}

The brains of mice were removed after decapitation. The striatum was quickly dissected and frozen in liquid nitrogen. Total RNA was isolated using TRIzol reagent (Thermo Fisher Scientific, USA) according to the manufacturer's protocol. Concentrations and purity of isolated DNA and RNA were determined with NanoDrop 2000c spectrophotometer (Thermo Fisher Scientific, USA). RNA extracts were immediately subjected to reverse transcription using FastQuant RT Kit (TIANGEN, China).

The qPCR assays for gene expression analysis were performed by adding $0.5 \mu$ of cDNA sample, $5 \mu \mathrm{l}$ Power SYBR Green PCR Master Mix (Thermo Fisher Scientific, USA), $0.5 \mu$ l each primer and RNase free water to a $10 \mu$ total volume. The reaction was initiated with activation of Taq polymerase by heating at $95^{\circ} \mathrm{C}$ during 2 min followed by 40 cycles of a 15 s denaturation step at $95^{\circ} \mathrm{C}$ and a $15 \mathrm{~s}$ annealing and elongation step at $60^{\circ} \mathrm{C}$. The fluorescence was measured after the extension step by the QuantStudio 5 Real-time PCR system (Thermo Fisher Scientific, USA). After the thermocycling reaction, a melting curve was performed with slow heating, starting at $55^{\circ} \mathrm{C}$ and with a rate of $0.5^{\circ} \mathrm{C}$ per $10 \mathrm{~s}$, up to $95^{\circ} \mathrm{C}$. The assay included a non-template control (sample was substituted by RNase- Dnase-free sterile water). All reactions ran in triplicates. 
Table 1

qRT-PCR primers sequence.

\begin{tabular}{|lll|}
\hline Primer & Forward $\left(\mathbf{5}^{\prime} \rightarrow \mathbf{3}^{\prime}\right)$ & Reverse $\left(\mathbf{5}^{\prime} \rightarrow \mathbf{3}^{\prime}\right)$ \\
\hline Gria1 & GCCCTGAGAGGTCCCGTAAA & CGGAGTCCTTGCTTCCACAT \\
\hline Gria2 & TCGGGTAGGGATGGTTCAGT & GGGAGCAGAAAGCATTGGTG \\
\hline Grin1 & ATGCGCGTCTACAACTGGAA & TTCTCTGCCTTGGACTCACG \\
\hline Grin2a & CCATTGGGAGCGGGTACATC & CTCTTCCATCTCACCGTCACC \\
\hline Grin2b & GCCATGAACGAGACTGACCC & GCTTCCTGGTCCGTGTCATC \\
\hline Actb & GGCTGTATTCCCCTCCATCG & CCAGTTGGTAACAATGCCATGT \\
\hline
\end{tabular}

\subsection{Statistical analysis}

Data analysis was performed using Prism 8 software (GraphPad Software, USA). Details on statistical analyses, including performed tests, $P$ values and sample sizes, are provided with the results or in figure legends. Briefly, for comparisons among three or four groups, one-way repeated measure analysis followed by Tukey post hoc comparison tests were used. For analysis of motor abilities, Sholl analysis and input-output curve, two-way ANOVA were conducted, followed by Tukey post hoc test. The $P$ value for significance was set at 0.05 . Data were expressed as mean \pm SEM.

\section{Results}

\subsection{EA ameliorated motor skill deficits in partial-lesioned mice}

The present experiment, unilateral 6-OHDA injection in the striatum induced a partial reduction of $\mathrm{TH}$ positive fibers in the ipsilateral striatum (Fig. 2a, b; $P<0.0001$ ) and TH immunoreactive neurons in the ipsilateral SNc (Fig. 2a, v; $P=0.013$ ). Western blotting revealed that TH expression was decreased in 6OHDA mice compared with sham mice (Fig. $2 d, P<0.0001$ ). We also examined DA concentration in the striatum using HPLC. The level of DA was decreased in 6-OHDA-treated mice (Fig. 2e, $P=0.008$ ). These data validate that 6-OHDA-treated mice are conformed to the standards of a partial-lesioned parkinsonism model, which mimics the early PD pathology. EA treatment for 4 weeks increased TH immunoreactive terminals (Fig. 2a, b; $P=0.002$ ) and TH protein expression (Fig. $2 \mathrm{~d}, \mathrm{P}=0.001$ ) in the striatum. However, EA had no significant influences over the dopaminergic neuronal degeneration in the SNc (Fig. 2a, C), the release of DA or DA metabolites in the striatum (Fig. 2e, Fig. S2a-c), and the transcription levels of DA receptors (Fig. S5). Thus, it seems that EA treatment exerted region-dependent neuroprotection of the dopaminergic innervation in the local striatum, but not dopaminergic neurons in the SNc. In addition, the impact of EA stimulation on the striatal neuronal response was detected in this 
experiment. The expression of c-fos, a marker of neuronal activation, obviously elevated in the ipsilateral dorsolateral striatum in both sham (Fig. S1, $P=0.034$ ) and model group (Fig. S1, $P=0.005$ ), indicating the activation of striatal neurons by an acute EA stimulation.

After 4-week EA treatment, we found that both the total movement distance in open field test (Fig. 2f; week $4, P=0.009$ ) and the latency time in rotarod test (Fig. 2g; week 4, $P=0.038$ ) were significantly increased as compared with 6-OHDA mice that did not receive EA. Thus, EA alleviated the gross motor behaviors, including ambulatory activity and coordinated balance ability, in the partial-lesioned mice. We also performed staircase test to detect the grasping ability of ipsilateral and contralateral forepaws of mice, which has been established to measure fine motor skills [33]. Although the number of pellets retrieved by ipsilateral forepaws remained relatively stable among three groups (Fig. 2i), the number of pellets retrieved by contralateral forepaws in EA-treated 6-OHDA mice were significantly lower than that seen in sham mice before and 2 weeks after EA treatment (Fig. 2h). However, EA obviously improved the grasping performance in 6-OHDA mice at the end of 4th week. Thus, EA treatment alleviated both the gross and fine motor skills in the partial-lesioned 6-OHDA mice, which likely involves the modulatory effect of EA on target(s) within the local striatum.

\subsection{EA did not alter structural plasticity of striatal MSNs.}

Due to the fact that 4-week EA interference was a chronic treatment, we set forth to determine whether chronic EA treatment modified striatal neuronal morphology. We traced striatal MSNs and their dendrites using biocytin-filled pipette solution during patch-clamp recordings to detect cellular morphology and complexity of these cells (Fig. 3a-c). Although the Sholl analysis displayed that dendrites 56-89 $\mu \mathrm{m}$ from soma exhibited less intersections in 6-OHDA mice compared to sham mice (Fig. 3d), the total branch points (Fig. 3e) and terminal points (Fig. 3f) showed no alterations among three groups. We also detected the dendrites of MSNs and there was neither difference in the density (Fig. 3g) nor morphology (Fig. S3af) of MSN spines. Taken together, in partial-lesioned mice, the complexity of dendritic arborization of MSNs and striatal synapses remain intact, while EA did not alter the structural plasticity.

\subsection{EA rescued striatal LTP in partial-lesioned mice}

We next set out to detect functional alterations of synaptic plasticity in the corticostriatal pathway. To this end, we used a microelectrode array system to record field EPSPs in the striatum (Fig. S4). The inputoutput curve (Fig. 4a) and PPR (Fig. 4b) were similar among three groups surveyed, indicating that basal synaptic transmission and presynaptic release were intact in 6-OHDA mice with or without EA treatment. The intact LTD (Fig. 4c) in 6-OHDA-treated mice is consistent with the result from the previous report [7], which established the phenotype of the partial DA denervation model of PD. Notably, LTP could not be induced in the striatum of 6-OHDA mice (Fig. 4d; $P=0.019$ ), whereas it was readily induced in 6-OHDA+ EA group (Fig. 4d; $P=0.012$ ). Another type of LTP known as chemical LTP is induced by glycine. Similar to the LTP induced by high frequency electrical stimulation, glycine induced a complete LTP in sham group and the blunted LTP in 6-OHDA lesioned group (Fig. 4e, $\mathrm{P}<0.0001$ ). Interestingly, this glycinemediated blunted LTP was effectively reversed by EA treatment (Fig. 4e, $\mathrm{P}<0.0001$ ). Additionally, we did 
not observe changes of glutamate concentrations in the striatum after either 6-OHDA lesion or EA treatment (Fig. 5f). Overall, these data imply that EA treatment selectively rescued the disrupted LTP, likely via a mechanism involving the postsynaptic rather than presynaptic elements, in our partial-lesioned model of PD.

\subsection{EA rescued AMPA and NMDA receptor-mediated synaptic activities in striatal MSNs}

To examine the effect of EA on glutamate receptor activity in striatal MSNs, we performed patch-clamp recordings of MSN that labeled with biocytin, targeting corticostriatal synaptic circuity in the dorsolateral striatum. AMPA receptor-mediated mEPSCs were recorded at $-70 \mathrm{mV}$ under whole-cell voltage clamp (Fig. 5a). The amplitude of mEPSCs in 6-OHDA mice were decreased compared to sham mice (Fig. 5b, $\mathrm{P}$ $=0.008$ ). This decrease was rescued in EA-treated mice (Fig. 5b; $P=0.001$ ). In contrast, the mEPSC frequency was not altered among three groups (Fig. 5C), indicating that presynaptic neurotransmitter release was intact. These results together suggest that the partial dopaminergic lesion impairs synaptic transmission at the postsynaptic but not presynaptic site. In addition, we observed no significant changes in the AMPA/NMDA ratio in the dorsolateral striatal MSNs following 6-OHDA intervene alone or 6-OHDA+ EA treatment (Fig. 5d, e), indicating that both AMPA- and NMDA-mediated EPSCs were altered by 6-OHDA or 6-OHDA + EA to a similar extent.

Given the above electrophysiological findings, neurochemical assays were carried out to analyze changes in the expression of AMPA and NMDA receptors in the striatum. We observed a decrease in protein levels of AMPA receptor GluA1 (Fig. 6a, P = 0.027), although not GluA2 (Fig. 6b), and NMDA receptor GluN1 (Fig. 6c, $P=0.004$ ), although not GluN2A (Fig. 6d) and GluN2B (Fig. 6e), subunits in 6-OHDA mice. EA treatment restored the expression of GluA1 (Fig. 6a, $P=0.035$ ) and GluN1 (Fig. 6c, P = 0.043). Consistently, qRT-PCR assays revealed that EA treatment restored the downregulation of Gria 1 (Fig. $6 \mathrm{f}$, sham vs. 6-OHDA, $P=0.048 ; 6-\mathrm{OHDA}$ vs. 6-OHDA + EA, $P=0.017$ ) and Grin1 (Fig. 6h; sham vs. 6-OHDA $P$ $=0.031,6-\mathrm{OHDA}$ vs. 6-OHDA + EA $P=0.025)$ in 6-OHDA group, two genes encoding GluA1 and GluN1, respectively. However, EA did not change levels of Gria2 (Fig. 6g), Grin2a (Fig. 6i), and Grin2b (Fig. 6j). These data provide evidence at the gene expression level, which are consistent with the findings above at the protein level. Apparently, the 6-OHDA-induced partial lesion selectively targeted GluA1 and GluN1 subunits. The downregulation of these subunits disrupted glutamatergic signaling in the striatum of 6OHDA-lesioned mice, whereas EA was able to reverse the loss of GluA1 and GluN1 subunits in response to 6-OHDA.

\subsection{Antagonists of AMPA and NMDA receptors inhibited the effects of EA on striatal LTP}

We further clarified the role of AMPA and NMDA receptors in processing the effect of EA on LTP, in the presence of their antagonists. The AMPA receptor antagonist CNQX was bath-perfused during LTP 
recordings in sham or EA-treated mice. We observed that LTP, albeit present, was significantly decreased in its amplitude compared to that in the control ACSF perfusate (Fig. 4d, 6 k), showing that blockade of AMPA receptors inhibited LTP in slices from sham and EA-treated mice. On the contrary, (s)-AMPA, an agonist of AMPA receptors, significantly reversed the reduction of LTP in 6-OHDA mice (Fig. 6k). These evidences support that AMPA receptor activity is required for the effect of EA on LTP. Similarly, the role of NMDA receptors on LTP was observed. Activation of NMDA receptors with glycine significantly restored the diminished LTP in 6-OHDA mice (Fig. 6I). DCKA, an NMDA receptor antagonist, decreased the fEPSC amplitude in the slices from both sham and EA-treated mice (Fig. 6l). These results substantiate the notion that both AMPA and NMDA receptors participate in the effectiveness of EA in restoring synaptic plasticity in the striatum of partial-lesioned mice.

\section{Discussion}

In contrast to the 6-OHDA injection into the MFB which leads to motor impairments resembling the advanced phase of PD, the injection of 6-OHDA into the striatum mimics the early phase of PD as a result of partial damage of the local dopaminergic system. In the present study, 6-OHDA was stereotaxically injected into two sites of the right striatum, which resulted in degeneration of $42 \%$ nigral dopaminergic cells and loss of $64 \%$ of striatal fibers. Meanwhile, a moderate DA depletion $(70 \%)$ was found in the striatum of 6-OHDA mice, indicating a partial loss of DA contents in PD mice [7]. In a different partial model generated by intranigral administration of the proteasome inhibitor lactacystin, a moderate impairment of motor coordination occurred in the rotarod performance [14]. In addition, unilateral injection of 6-OHDA into the MFB at a low dose $(3 \mu \mathrm{g})$ caused mild motor deficits, including forelimb akinesia in the stepping test [8]. Intracerebroventrical infusion of 6-OHDA induced forelimb grasping inability in mice, which was assessed as an earlier motor sign and accepted as bradykinesia in PD [34]. Consistent with these findings, our partially lesioned mice with 6-OHDA showed impaired motor skills, including reduced movement distance and shortened latency time. Besides these gross motor defects, the fine motor impairment such as forelimb grasping activities was reduced as well. Given the good correlation between motor phenotypes and degree of DA denervation [8], behavioral and biochemical changes we observed indicate a partial lesion in the striatum, which largely mimics an early stage of PD.

Evidences revealed that acupuncture or EA could ameliorate motor symptoms and reduce dopaminergic neuronal degeneration in PD models [35-38]. In our present experiment, chronic EA treatment ameliorated gross motor signs (ambulatory activity and coordinated balance ability) and fine forelimb motor performance in a partial-lesioned model. In details, the partial lesion in the striatum was sufficient to trigger deficits of motor skills, such as the reduction of movement and the slow execution of movements [34], cardinal features of PD observed during the early stage. EA mitigated the striatal lesion and behavioral deficits in a closely correlated manner. However, our results suggest that EA did alleviate motor skills but not prevent the degeneration of nigral dopaminergic neurons (Fig. 2a, c). Contrasting with application of EA immediately after toxic administration [35] [36] [37], we delivered EA two weeks after 6OHDA lesion. Thus, it is speculated that chronic 6-OHDA lesion induced irreversible neuronal death in the SNc which could not be reversed by subsequent EA treatment [39]. Although the different acupoints were 
utilized in other studies [35, 37], EA performed at these acupoints (ST36 and SP6) is known to effectively relieve motor symptoms in PD mice $[24,26]$. Thus, EA achieves its motor effect in the early stage of the disease by modulating the striatal function without restoring the loss of nigral dopaminergic neurons.

In the DA-denervated model of PD, morphological findings showed that spine density is significantly reduced in striatal MSNs [40]. However, in the partial PD model induced with lactacystin, an insignificant change in the density of postsynaptic spine was seen, while a significant increase in both the length and area of postsynaptic density occurred at corticostriatal synapses [14]. Similarly, we observed a slight but not significant reduction in the density of postsynaptic spines in the partial-lesioned 6-OHDA model. Further studies need to determine whether morphological alterations act as a compensatory mechanism to maintain motor function under conditions of partial dopamine depletion.

The deficits in functional synaptic plasticity may precede the dendrite atrophy during the early period of DA depletion. In fact, an early study found that the complete depletion of striatal DA led to the loss of both LTP and LTD at corticostriatal synapses, while an incomplete DA denervation altered the LTP but not LTD at these synapses [7]. Other studies with transgenic mice also revealed early changes in corticostriatal plasticity [41]. In the present study, EA did not significantly improve morphological plasticity or LTD, while it reversed the deficits in LTP and meanwhile improved motor skills in the partiallesioned model. Therefore, the functional specific modulatory effects of EA on striatal synaptic plasticity, especially LTP, could serve as a synaptic mechanism underlying the EA-induced improvement of motor skills. This evidence demonstrated that the new role of EA is to modulate the functional strength of corticostriatal synapses in the partial-lesioned PD model.

Synaptic plasticity in the striatum is regulated by the interaction between two major local transmitters, DA and glutamate $[42,43]$. Garcia-Munoz et al. have postulated that DA presynaptically inhibits the release of glutamate from corticostriatal terminals in the striatum [42]. As a result, a complete denervation of DA causes an increase in local glutamate release, which may represent an important physiological feature of PD and underlie motor deficits in the parkinsonian state. However, in the partially DA-depleted striatum, no changes were found in basal extracellular levels of glutamate in 6-OHDA treated rats [44]. Consistent with this observation, no significant change in glutamate levels was observed in the partial DA-depleted striatum in our experiments. Together, these findings suggest that after partial loss of DA, a lower but significant level of DA retained in the striatum, which may sufficiently carry out its function in inhibiting local glutamate release.

Thus, it is interesting to investigate whether any changes in glutamate receptors occur in the partial DAdepleted striatum in light of the lack of changes in glutamate release. A possible assumption is that the maladaptive response of glutamate receptors participated in the compensatory mechanisms underlying the early symptoms of PD. LTP is NMDA receptor-dependent in the striatum, while LTD is not [45]. NMDA receptors are abundant in the striatum, consisting of GluN1, GluN2A and GluN2B subunits. We found that in the partial DA-depleted striatum, expression of GluN1 subunits was decreased, while GluN2A and GluN2B subunits were unchanged. Similar reduction of GluN1 expression was previously reported in both 
6-OHDA-treated rats and MPTP-treated monkeys [46, 47]. Perhaps the loss of GluN1 subunits causes downregulation of NMDA receptor activity, leading to the LTP failure and the final motor skills deficits. However, Paille et al. reported that GluN2A and GluN2B subunits were increased and decreased, respectively, to produce mild motor symptoms in a partial lesion rat model of PD [7]. This underscores the complex of roles of different NMDA subunits in constructing synaptic plasticity and motor activity in response to different models of PD.

In addition to NMDA receptors, we monitored AMPA receptor activity by recording whole-cell mEPSCs. We found no alteration in the frequency of mEPSCs, whereas the magnitude of mEPSCs was decreased in 6OHDA-lesioned mice. It implies that the number of AMPA receptors was downregulated in the postsynaptic MSNs. In support of this, neurochemical assays revealed that GluA1 expression was reduced in the striatum of PD mice [48]. It has been demonstrated that incorporation of GluA1-containing AMPA receptors into synaptic membranes is a crucial mechanism for LTP and the reduction of GluA1 is thus bound to weaken LTP [49]. In the present work, the reduction of mRNA and protein expression of GluN1 and GluA1 in PD mice was reversed by EA treatment. Meanwhile, the disrupted LTP in PD mice was recovered following EA treatment. Furthermore, AMPA and NMDA receptor antagonists blocked the effect of EA on LTP. These data support a notion that GluN1 and GluA1 subunits are key substrates of EA for normalizing the corticostriatal LTP in a partial-lesioned model of PD.

\section{Conclusions}

In summary, we uncovered that chronic EA administration improved the motor skills in a partial-lesioned model of PD. EA has been shown to affect the glutamate receptor-dependent striatal synaptic plasticity without interfering the degeneration of dopamine neurons. Indeed, pharmacological antagonism of NMDA and AMPA receptors prevented the benefit effect of EA on the LTP form of synaptic plasticity. Thus, EA through manipulating specific glutamate receptors can reverse synaptic abnormalities and alleviate motor skills in the partial-lesioned model of PD.

\section{Abbreviations}

EA, electro-acupuncture; PD, Parkinson's disease; SNc, substantia nigra pars compacta; LTP, long-term potentiation; LTD, long-term depression; 6-OHDA, 6-hydroxydopamine; APO, apomorphine; HPLC, High performance liquid chromatography; $\mathrm{TH}$, tyrosine hydroxylase; MSNs, medium spiny neurons; PPR, paired-pulse ratio; HFS, high-frequency stimulation; fEPSPs, field excitatory postsynaptic potentials; mEPSCs, miniature excitatory postsynaptic currents; AMPA, a-amino-3-hydroxy-5-methyl-4-isoxazole propionic acid; NMDA, N-methyl-D-aspartate; TTX, tetrodotoxin; PTX, picrotoxin; CNQX, 6-Cyano-7nitroquinoxaline-2,3-dione; (s)-AMPA, (s)-a-Amino-3-hydroxy-5-methylisoxazole-4-propionic acid; DCKA, 5,7-Dichlorokynurenic acid; DOPAC, 3,4, dihydroxyphenylacetic acid; HVA, homovanillic acid

\section{Declarations}




\section{Ethics approval and consent to participate}

All experimental procedures were approved by the Animal Ethics Committee of Capital Medical University and carried out in accordance with National Institutes of Health Guide for the Care and Use of Laboratory Animals.

\section{Consent for publication}

Not applicable.

\section{Availability of data and materials}

Data sharing is not applicable to this article as no datasets were generated or analyzed during the current study.

\section{Competing interests}

The authors declare that they have no competing interests.

\section{Funding}

This study was supported by the National Natural Science Foundation of China $(81774398,81704151$, 81873364 and 61701323); Beijing Natural Science Foundation (7172033, 7202013); Scientific Research Common Program of Beijing Municipal Commission of Education (KM201710025014); and a special fund from Key laboratory of Neurodegenerative diseases, Ministry of Education (PXM2019-026283000002).

\section{Authors' contributions}

Conceptualization: SWT; Investigation: SWT, YJN and LM; Formal analysis: SWT, YJN and LC; Methodology: WK; Writing: SWT, YJN and JJ; Supervision: JJ and WXM. All authors read and approved the final submission.

\section{Acknowledgements}

We express our sincere thanks to Dr. John Q. Wang (University of Missouri-Kansas City) for his critical reading of the manuscript; and to Dr. Lei Liu (Beijing Institute of Brain Disorders, Capital Medical University) for his suggestions to the project.

\section{References}


1. Dauer W, Przedborski S. Parkinson's disease: mechanisms and models. Neuron. 2003;39(6):889909.

2. Lang AE, Lozano AM. Parkinson's disease. First of two parts. N Engl J Med. 1998;339(15):1044-53.

3. Nandhagopal R, McKeown MJ, Stoessl AJ. Functional imaging in Parkinson disease. Neurology. 2008;70(16 Pt 2):1478-88.

4. Marsden CD. Parkinson's disease. Lancet. 1990;335(8695):948-52.

5. Armstrong MJ, Okun MS. Diagnosis and Treatment of Parkinson Disease: A Review. Jama. 2020;323(6):548-60.

6. Ungerstedt U. 6-Hydroxy-dopamine induced degeneration of central monoamine neurons. Eur J Pharmacol. 1968;5(1):107-10.

7. Paille V, Picconi B, Bagetta V, Ghiglieri V, Sgobio C, Di Filippo M, Viscomi MT, Giampa C, Fusco FR, Gardoni F, et al. Distinct levels of dopamine denervation differentially alter striatal synaptic plasticity and NMDA receptor subunit composition. The Journal of neuroscience: the official journal of the Society for Neuroscience. 2010;30(42):14182-93.

8. Boix J, Padel T, Paul G. A partial lesion model of Parkinson's disease in mice-characterization of a 6OHDA-induced medial forebrain bundle lesion. Behav Brain Res. 2015;284:196-206.

9. Hernando S, Requejo C, Herran E, Ruiz-Ortega JA, Morera-Herreras T, Lafuente JV, Ugedo L, Gainza E, Pedraz JL, Igartua $M$, et al. Beneficial effects of $n-3$ polyunsaturated fatty acids administration in a partial lesion model of Parkinson's disease: The role of glia and NRf2 regulation. Neurobiol Dis. 2019;121:252-62.

10. Villalba RM, Mathai A, Smith Y. Morphological changes of glutamatergic synapses in animal models of Parkinson's disease. Front Neuroanat. 2015;9:117.

11. Imbriani P, Schirinzi T, Meringolo M, Mercuri NB, Pisani A. Centrality of Early Synaptopathy in Parkinson's Disease. Front Neurol. 2018;9:103.

12. Chu HY: Synaptic and cellular plasticity in Parkinson's disease. Acta pharmacologica Sinica 2020.

13. Wichmann T. Changing views of the pathophysiology of Parkinsonism. Movement disorders: official journal of the Movement Disorder Society. 2019;34(8):1130-43.

14. Bentea E, Moore C, Deneyer L, Verbruggen L, Churchill MJ, Hood RL, Meshul CK, Massie A. Plastic changes at corticostriatal synapses predict improved motor function in a partial lesion model of Parkinson's disease. Brain Res Bull. 2017;130:257-67.

15. Alberquilla S, Gonzalez-Granillo A, Martin ED, Moratalla R. Dopamine regulates spine density in striatal projection neurons in a concentration-dependent manner. Neurobiol Dis. 2020;134:104666.

16. Kreitzer AC, Malenka RC. Endocannabinoid-mediated rescue of striatal LTD and motor deficits in Parkinson's disease models. Nature. 2007;445(7128):643-7.

17. Picconi B, Centonze D, Hakansson K, Bernardi G, Greengard P, Fisone G, Cenci MA, Calabresi P. Loss of bidirectional striatal synaptic plasticity in L-DOPA-induced dyskinesia. Nature neuroscience. 2003;6(5):501-6. 
18. Paille V, Henry V, Lescaudron L, Brachet P, Damier P. Rat model of Parkinson's disease with bilateral motor abnormalities, reversible with levodopa, and dyskinesias. Movement disorders: official journal of the Movement Disorder Society. 2007;22(4):533-9.

19. Toosizadeh N, Lei H, Schwenk M, Sherman SJ, Sternberg E, Mohler J, Najafi B. Does integrative medicine enhance balance in aging adults? Proof of concept for the benefit of electroacupuncture therapy in Parkinson's disease. Gerontology. 2015;61(1):3-14.

20. Yeo S, van den Noort M, Bosch P, Lim S. A study of the effects of 8-week acupuncture treatment on patients with Parkinson's disease. Medicine. 2018;97(50):e13434.

21. Jiang $F$, Yang T, Yin H, Guo Y, Namba $H$, Sun Z, Asakawa T. Evidence for the Use of Acupuncture in Treating Parkinson's Disease: Update of Information From the Past 5 Years, a Mini Review of the Literature. Front Neurol. 2018;9:596.

22. Jia J, Li B, Sun ZL, Yu F, Wang X, Wang XM. Electro-acupuncture stimulation acts on the basal ganglia output pathway to ameliorate motor impairment in Parkinsonian model rats. Behav Neurosci. 2010;124(2):305-10.

23. Wang $H$, Liang $X$, Wang $X$, Luo $D$, Jia J, Wang $X$. Electro-acupuncture stimulation improves spontaneous locomotor hyperactivity in MPTP intoxicated mice. PLoS One. 2013;8(5):e64403.

24. Yu Y, Wang K, Deng J, Sun M, Jia J, Wang X. Electroacupuncture Produces the Sustained Motor Improvement in 6-Hydroxydopamine-Lesioned Mice. PLoS One. 2016;11(2):e0149111.

25. Zhang R, Andersen AH, Hardy PA, Forman E, Evans A, Ai Y, Yue J, Yue G, Gash DM, Grondin R, et al. Objectively measuring effects of electro-acupuncture in parkinsonian rhesus monkeys. Brain research. 2018;1678:12-9.

26. Deng J, Lv E, Yang J, Gong X, Zhang W, Liang X, Wang J, Jia J, Wang X. Electroacupuncture remediates glial dysfunction and ameliorates neurodegeneration in the astrocytic alpha-synuclein mutant mouse model. J Neuroinflammation. 2015;12:103.

27. Chassain C, Melon C, Salin P, Vitale F, Couraud S, Durif F, Kerkerian-Le Goff L, Gubellini P. Metabolic, synaptic and behavioral impact of 5-week chronic deep brain stimulation in hemiparkinsonian rats. Journal of neurochemistry. 2016;136(5):1004-16.

28. Sun Z, Jia J, Gong X, Jia Y, Deng J, Wang X, Wang X. Inhibition of glutamate and acetylcholine release in behavioral improvement induced by electroacupuncture in parkinsonian rats. Neurosci Lett. 2012;520(1):32-7.

29. Zhen J, Qian Y, Weng X, Su W, Zhang J, Cai L, Dong L, An H, Su R, Wang J, et al. Gamma rhythm low field magnetic stimulation alleviates neuropathologic changes and rescues memory and cognitive impairments in a mouse model of Alzheimer's disease. Alzheimers Dement (N Y). 2017;3(4):487-97.

30. Ting JT, Daigle TL, Chen Q, Feng G. Acute brain slice methods for adult and aging animals: application of targeted patch clamp analysis and optogenetics. Methods Mol Biol. 2014;1183:22142.

31. Calabresi P, Pisani A, Mercuri NB, Bernardi G. Long-term Potentiation in the Striatum is Unmasked by Removing the Voltage-dependent Magnesium Block of NMDA Receptor Channels. Eur J Neurosci. 
1992;4(10):929-35.

32. Mazzocchi-Jones D. Impaired corticostriatal LTP and depotentiation following iPLA2 inhibition is restored following acute application of DHA. Brain Res Bull. 2015;111:69-75.

33. Mandel RJ, Randall PK. Quantification of lesion-induced dopaminergic supersensitivity using the rotational model in the mouse. Brain research. 1985;330(2):358-63.

34. Ribeiro RP, Santos DB, Colle D, Naime AA, Goncalves CL, Ghizoni H, Hort MA, Godoi M, Dias PF, Braga $A L$, et al. Decreased forelimb ability in mice intracerebroventricularly injected with low dose 6hydroxidopamine: A model on the dissociation of bradykinesia from hypokinesia. Behav Brain Res. 2016;305:30-6.

35. Zhao Y, Luo D, Ning Z, Rong J, Lao L. Electro-Acupuncture Ameliorated MPTP-Induced Parkinsonism in Mice via TrkB Neurotrophic Signaling. Front Neurosci. 2019;13:496.

36. Pak ME, Ahn SM, Jung DH, Lee HJ, Ha KT, Shin HK, Choi BT. Electroacupuncture Therapy Ameliorates Motor Dysfunction via Brain-Derived Neurotrophic Factor and Glial Cell Line-Derived Neurotrophic Factor in a Mouse Model of Parkinson's Disease. J Gerontol A Biol Sci Med Sci. 2020;75(4):712-21.

37. Park Hi -J, Lim S, Joo W-S, Yin C-S, Lee H-S, Lee H-J, Seo J-C, Leem K, Son Y-S, Kim Y-J, et al. Acupuncture prevents 6-hydroxydopamine-induced neuronal death in the nigrostriatal dopaminergic system in the rat Parkinson's disease model. Exp Neurol. 2003;180(1):93-8.

38. Lin JG, Chen CJ, Yang HB, Chen YH, Hung SY. Electroacupuncture Promotes Recovery of Motor Function and Reduces Dopaminergic Neuron Degeneration in Rodent Models of Parkinson's Disease. Int J Mol Sci 2017, 18(9).

39. Ko JH, Lee H, Kim SN, Park HJ. Does Acupuncture Protect Dopamine Neurons in Parkinson's Disease Rodent Model?: A Systematic Review and Meta-Analysis. Front Aging Neurosci. 2019;11:102.

40. Nishijima H, Ueno T, Funamizu Y, Ueno S, Tomiyama M. Levodopa treatment and dendritic spine pathology. Movement disorders: official journal of the Movement Disorder Society. 2018;33(6):87788.

41. Madeo G, Schirinzi T, Martella G, Latagliata EC, Puglisi F, Shen J, Valente EM, Federici M, Mercuri NB, Puglisi-Allegra S, et al. PINK1 heterozygous mutations induce subtle alterations in dopaminedependent synaptic plasticity. Movement disorders: official journal of the Movement Disorder Society. 2014;29(1):41-53.

42. Calabresi P, Pisani A, Mercuri NB, Bernardi G. The corticostriatal projection: from synaptic plasticity to dysfunctions of the basal ganglia. Trends Neurosci. 1996;19(1):19-24.

43. Jamwal S, Kumar P. Insight Into the Emerging Role of Striatal Neurotransmitters in the Pathophysiology of Parkinson's Disease and Huntington's Disease: A Review. Current neuropharmacology. 2019;17(2):165-75.

44. Abarca J, Bustos G. Differential regulation of glutamate, aspartate and gamma-amino-butyrate release by $\mathrm{N}$-methyl-D-aspartate receptors in rat striatum after partial and extensive lesions to the nigro-striatal dopamine pathway. Neurochem Int. 1999;35(1):19-33. 
45. Lovinger DM. Neurotransmitter roles in synaptic modulation, plasticity and learning in the dorsal striatum. Neuropharmacology. 2010;58(7):951-61.

46. Picconi B, Gardoni F, Centonze D, Mauceri D, Cenci MA, Bernardi G, Calabresi P, Di Luca M. Abnormal $\mathrm{Ca} 2+$-calmodulin-dependent protein kinase II function mediates synaptic and motor deficits in experimental parkinsonism. The Journal of neuroscience: the official journal of the Society for Neuroscience. 2004;24(23):5283-91.

47. Betarbet R, Poisik O, Sherer TB, Greenamyre JT. Differential expression and ser897 phosphorylation of striatal N-methyl-d-aspartate receptor subunit NR1 in animal models of Parkinson's disease. Exp Neurol. 2004;187(1):76-85.

48. Lai SK, Tse YC, Yang MS, Wong CK, Chan YS, Yung KK. Gene expression of glutamate receptors GluR1 and NR1 is differentially modulated in striatal neurons in rats after 6-hydroxydopamine lesion. Neurochem Int. 2003;43(7):639-53.

49. Hayashi Y, Shi SH, Esteban JA, Piccini A, Poncer JC, Malinow R. Driving AMPA receptors into synapses by LTP and CaMKII: requirement for GluR1 and PDZ domain interaction. Science. 2000;287(5461):2262-7.

\section{Figures}

A

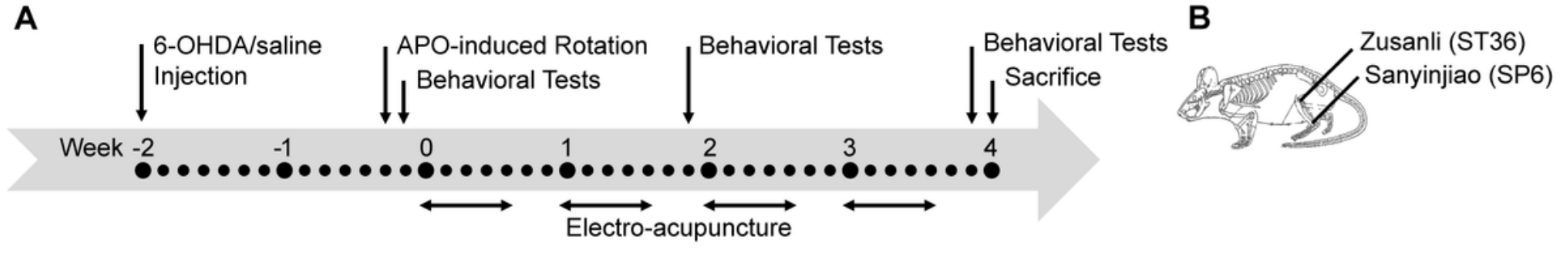

Figure 1

The time course and experimental layouts. a Mice were grouped into sham, 6-OHDA and 6-OHDA + EA, all unilaterally injected in the striatum at week -2 with either 6-OHDA or saline. Mice were administrated with chronic $100 \mathrm{~Hz}$ EA stimulation for 4 weeks (5 days per week). Behavior tests were performed at three time points, i.e. before week 0 and at the end of 2 nd and 4 th week. At the end of week 4 , mice were used for either electrophysiology experiments or sacrificed for biochemistry tests. $b$ The schematic diagram illustrating the position of two acupoints (Zusanli and Sanyinjiao) on the mouse hindlimbs for EA. 

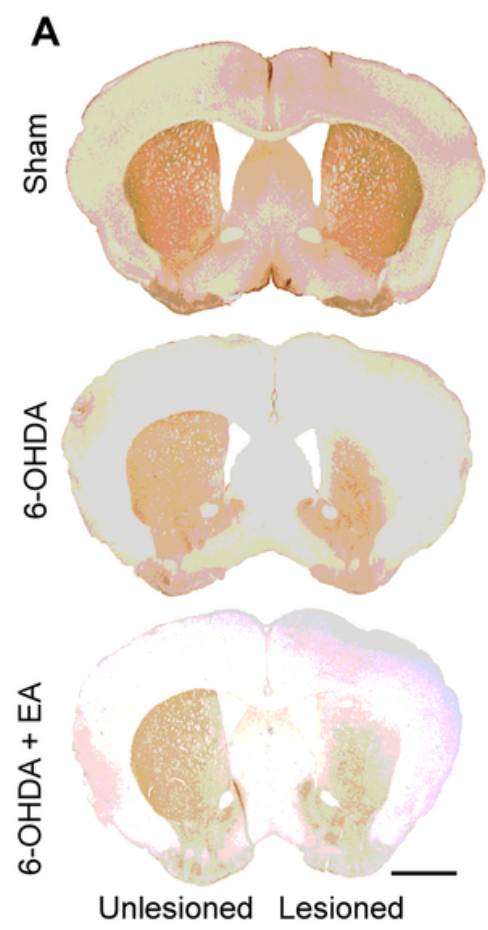

$\mathbf{F}$

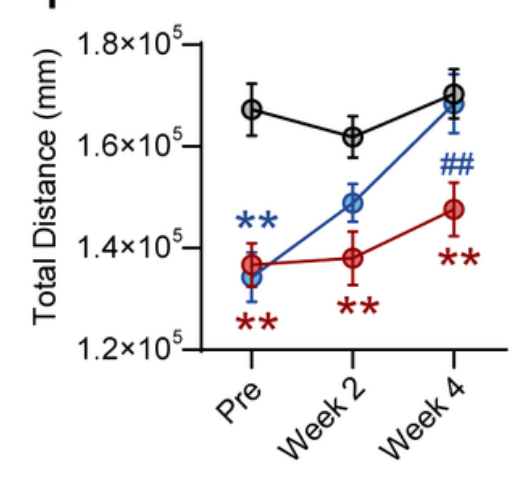

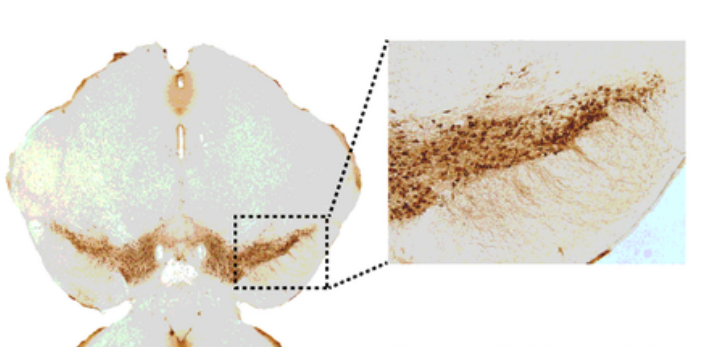
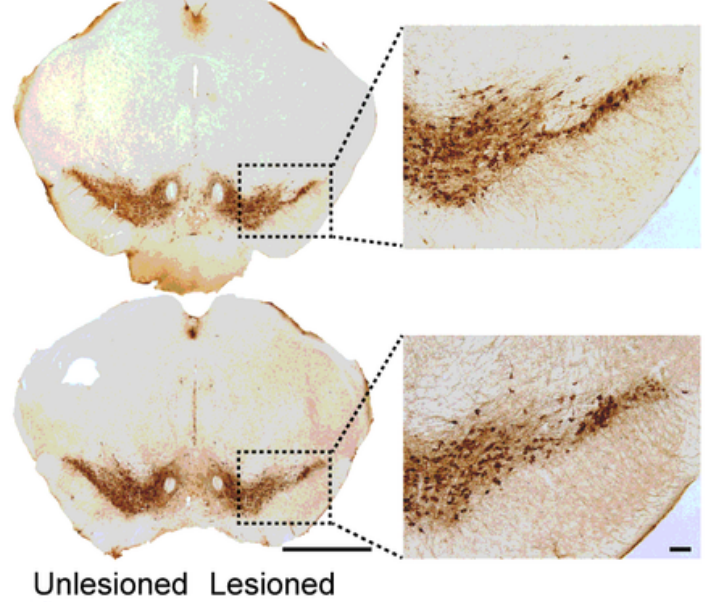

G

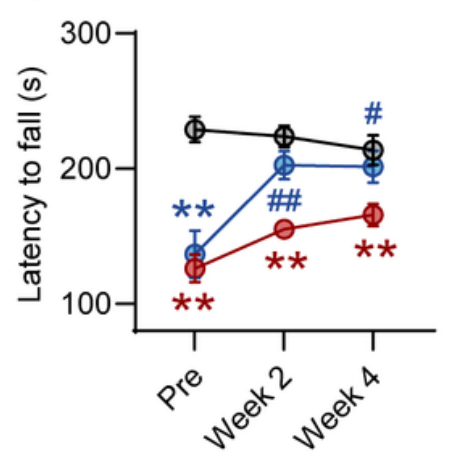

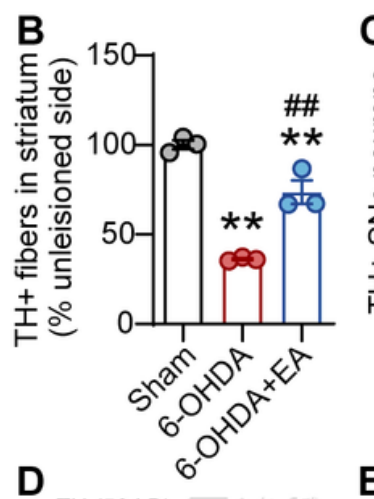
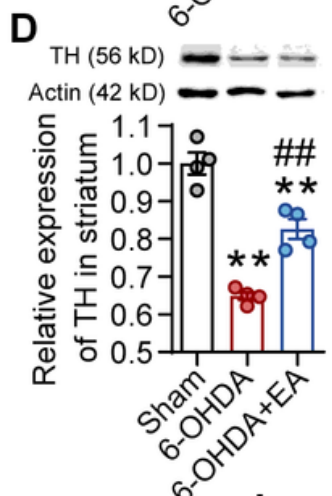

E
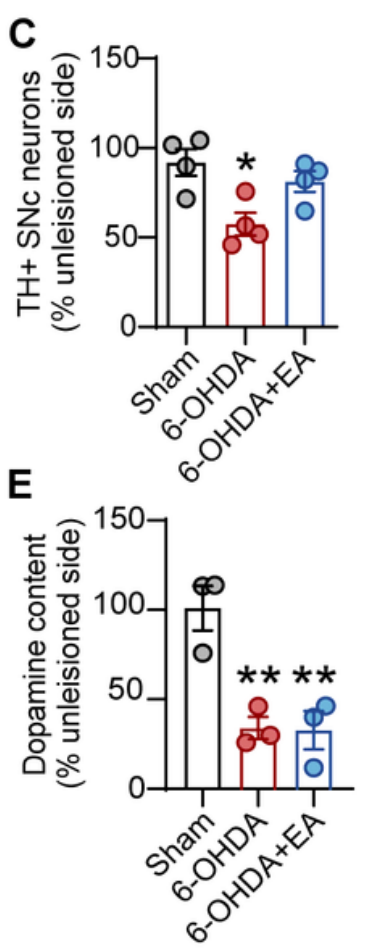

\section{Figure 2}

Chronic EA treatment attenuated motor deficits in partial-lesioned mice. a Representative images of TH positive dopaminergic fibers in the striatum (left) and neurons in the SNc (middle and right). Scale bar: 20 $\mu \mathrm{m}$ in the left and middle, $100 \mu \mathrm{m}$ in the right. b Relative optical density of TH positive dopaminergic fibers in the ipsilateral striatum compared to that in the unlesioned side, $\mathrm{N}=3$ per group. $\mathrm{c}$ The percentage of TH positive dopaminergic neurons in the ipsilateral SNc relative to that in the unlesioned side, $\mathrm{N}=4$ per group. $\mathrm{d}$ Protein level of $\mathrm{TH}$ in the striatum with $\beta$-action as loading control and normalized to sham group, $\mathrm{N}=4$ per group. e Relative content of DA in the ipsilateral striatum compared to that in the unlesioned side, $\mathrm{N}=3$ per group. $\mathrm{f}$ Locomotor activity of mice travelled in the open field in 30 minutes in three time points, $\mathrm{N}=18-24$ mice per group. $\mathrm{g}$ The time to fall off the rotarod was recorded as the latency of each mice in the rotarod test in three time points, $N=18-24$ mice per group. $h$, $i$ The number of pellets retrieved before week 0 and at the end of 2 nd and 4 th week, using contralateral $(h)$ and ipsilateral ( $i$ ) forepaws of mice, $\mathrm{N}=13-24$ mice per group. Data are expressed as mean $\pm \mathrm{SEM}$. One-way ANOVA analysis followed by Tukey post-test for the immunohistochemical, HPLC and western blot experiments. 
Two-way ANOVA analysis followed by Tukey post-test for the behavior tests. ${ }^{*} \mathrm{P}<0.05,{ }^{*} \mathrm{P}<0.01$ vs. sham group; \#P < 0.05, \#\#P < 0.01 vs. 6-OHDA group.

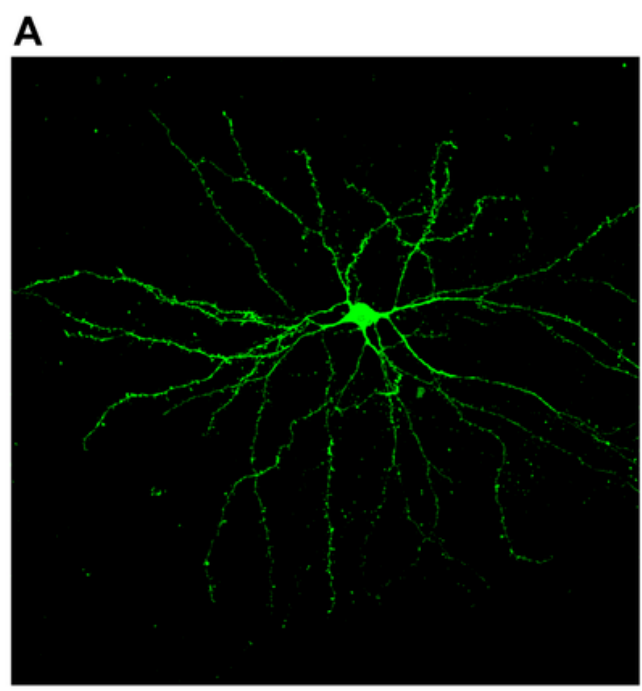

B

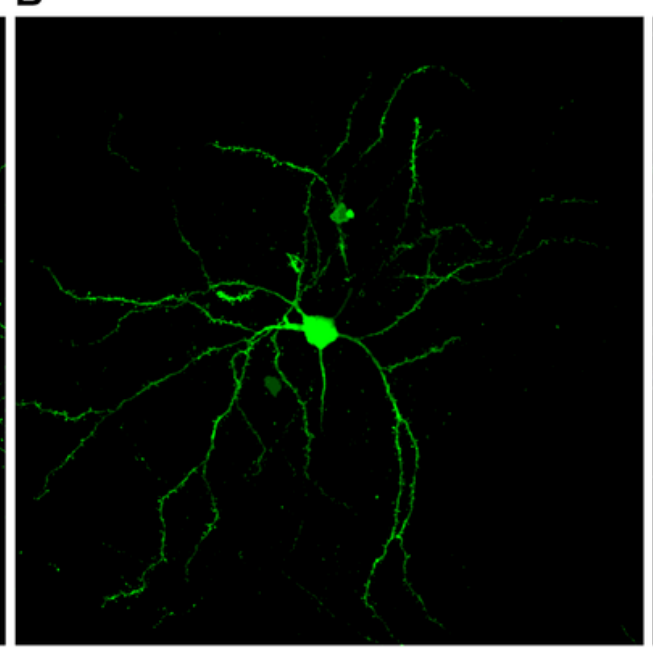

C
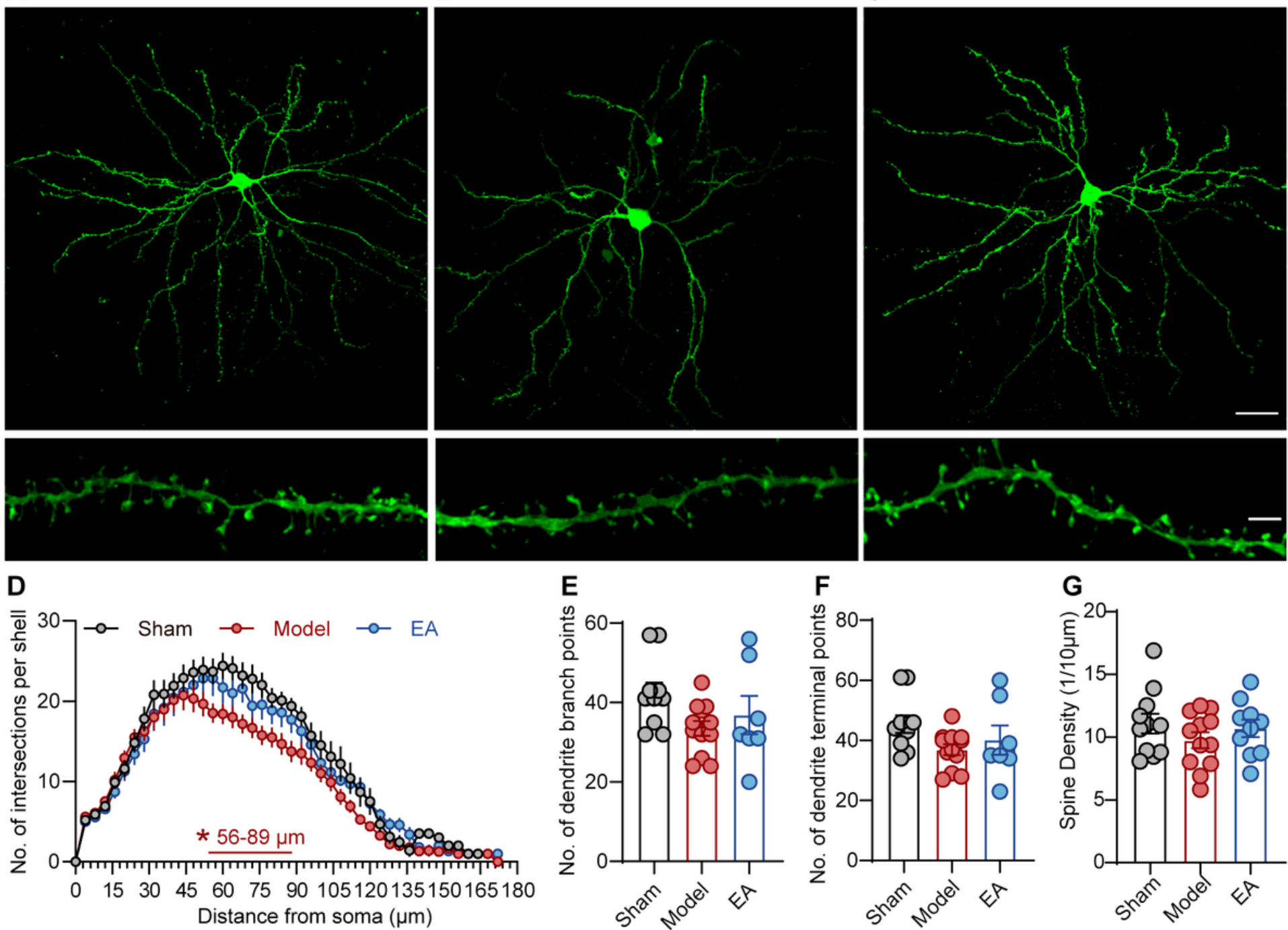

E
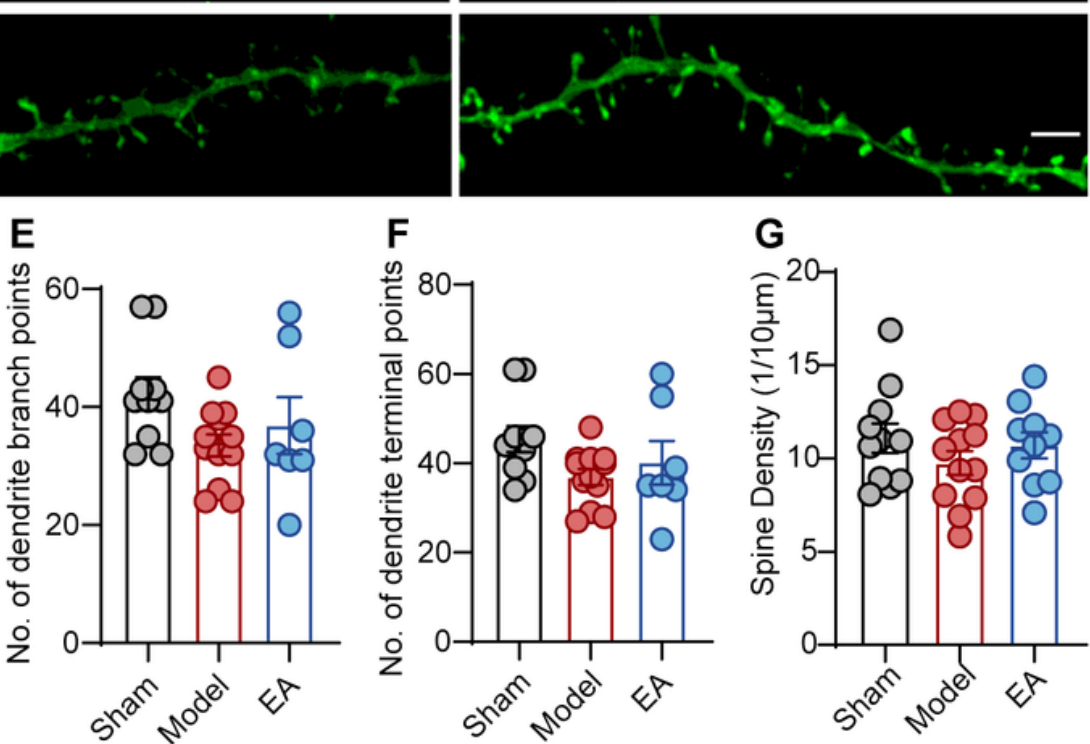

$\mathbf{F}$

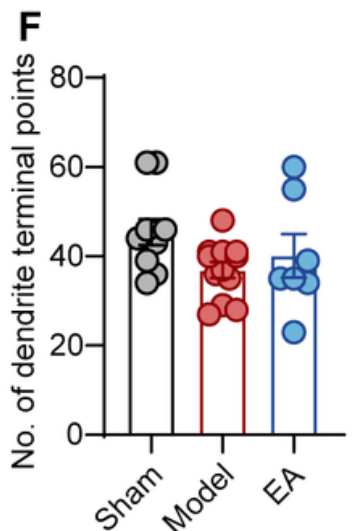

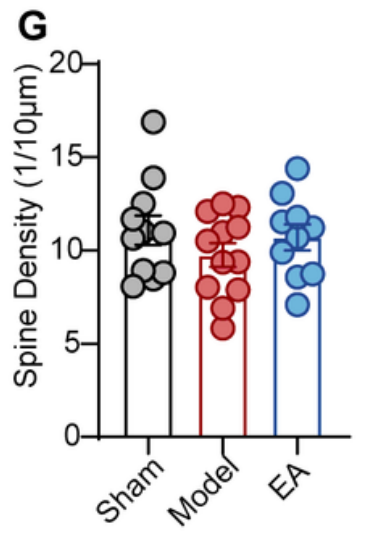

\section{Figure 3}

EA treatment did not affect structural plasticity of striatal MSNs. a-c Top, representative images of biocytin-filled striatal MSN and their dendritic branches, scale bar $=30 \mu \mathrm{m}$. Bottom, sample images showing dendrites and spines of striatal MSNs, scale bar = $5 \mu \mathrm{m}$. $\mathrm{d}$ A three-dimensional Sholl analysis of biocytin-filled and reconstructed neurons reveals the number of intersections of dendrites from the cell body of MSNs. $\mathrm{N}=10$ cells from 4 sham mice, 12 cells from 5 6-OHDA mice and 7 cells from 4 6-OHDA + EA mice. e The total number of dendritic branch points of the neurons in (d). $f$ The total number of dendritic terminal points of the neurons in $(\mathrm{d})$. $\mathrm{g}$ The total spine density of striatal MSNs. $\mathrm{N}=11$ cells from 4 sham mice, 12 cells from 5 6-OHDA mice and 10 cells from 4 6-OHDA + EA mice, each cell averaged by 3-4 dendrites. Data are expressed as means \pm SEM. One-way ANOVA analysis followed by Tukey post-test, expect that two-way ANOVA analysis followed by Tukey post-test for Sholl analysis. *P < 0.05 6-OHDA vs. sham group. 


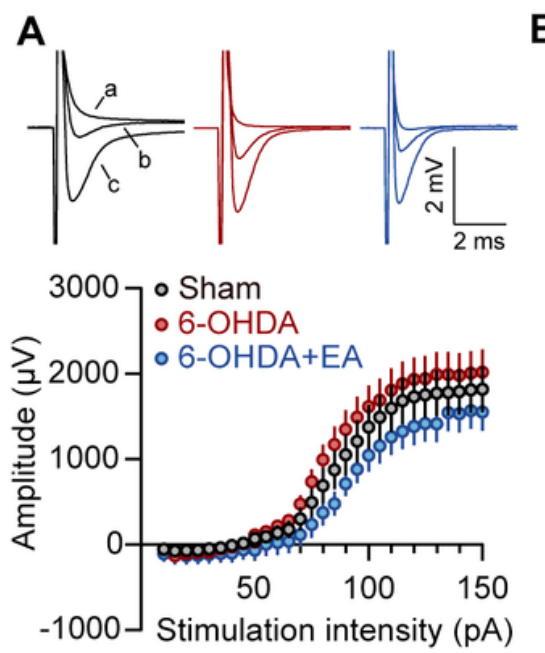

B

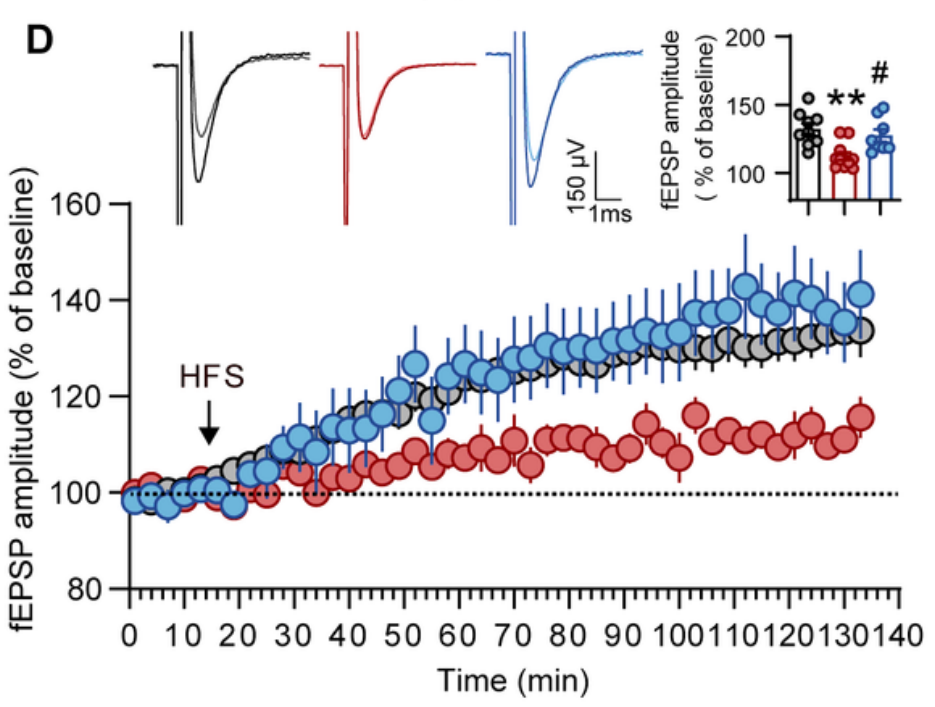

C
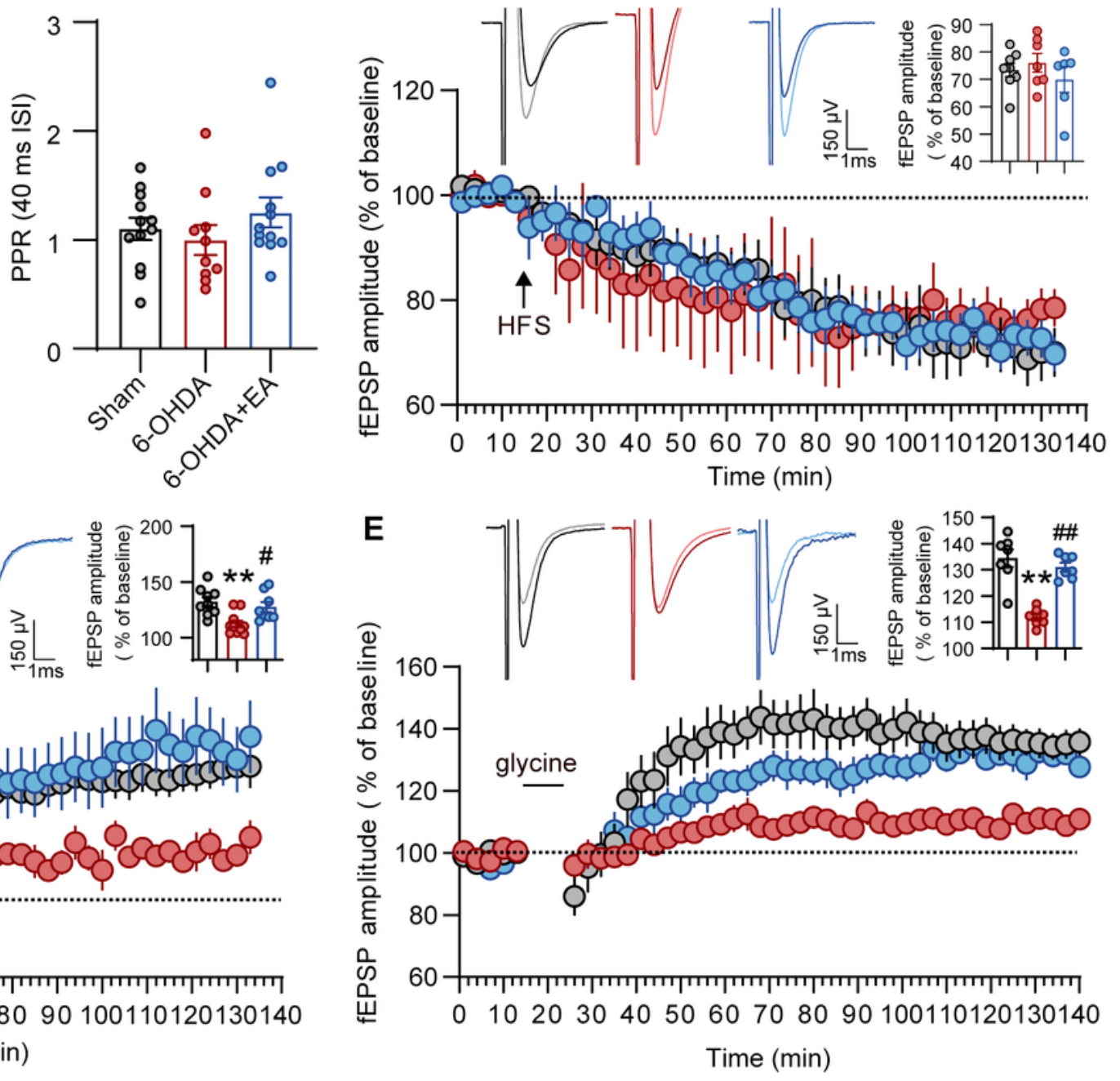

\section{Figure 4}

EA treatment rescued LTP defects in the striatum of partial-lesioned mice. a Top, representative traces of sham, 6-OHDA and 6-OHDA + EA slices evoked with stimulation intensity of 0, 75 and 150 pA, indicated by trace $a, b, c$, respectively. Bottom, input-output curve of dorsolateral striatum among sham, 6-OHDA and 6-OHDA + EA mice. $\mathrm{N}=7$ slices from 6 sham mice, 11 slices from 5 6-OHDA mice and 9 slices from 4 6-OHDA + EA mice. b Bar plot of PPR of MSNs from sham, 6-OHDA and 6-OHDA + EA group, interstimulus interval $(I S I)=40 \mathrm{~ms} . \mathrm{N}=12$ cells from 6 sham mice, 10 cells from $56-$ OHDA mice and 12 cells from 4 6-OHDA + EA mice. c Top, representative traces of sham, 6-OHDA and 6-OHDA + EA slices extracted within 0-15 min (light traces) and the last 10 min (dark traces). Bottom, cumulative data of LTD induced by HFS in the dorsolateral striatum. Insert, bar graph representing the average fEPSPs amplitude of the last 10 min after LTD induction. $\mathrm{N}=8$ slices from 3 sham mice, 7 slices from 36 -OHDA mice and 6 slices from 3 6-OHDA + EA mice, $P=0.496$. $d$ Top, representative traces of sham, 6-OHDA and 6-OHDA + EA slices extracted within 0-15 min and the last $10 \mathrm{~min}$. Bottom, cumulative data of LTP induced by HFS in the dorsolateral striatum. Insert, bar graph representing the average fEPSPs amplitude of the last 10 min after LTP induction. $\mathrm{N}=9$ slices from 6 sham mice, 11 slices from 5 6-OHDA mice and 8 slices from 4 6-OHDA + EA mice, $\mathrm{P}=$ 0.002. e Top, representative traces of sham, 6-OHDA and 6-OHDA + EA slices 
extracted within 0-15 min and the last $10 \mathrm{~min}$. Bottom, summary data of LTP induced by $150 \mu \mathrm{M}$ glycine in the dorsolateral striatum. Insert, bar graph representing the average fEPSPs amplitude of the last 10 min after LTP induction. $N=7$ slices from 3 sham mice, 7 slices from 3 6-OHDA mice and 7 6-OHDA + slices from 3 EA mice, $P<0.001$.

A

Sham

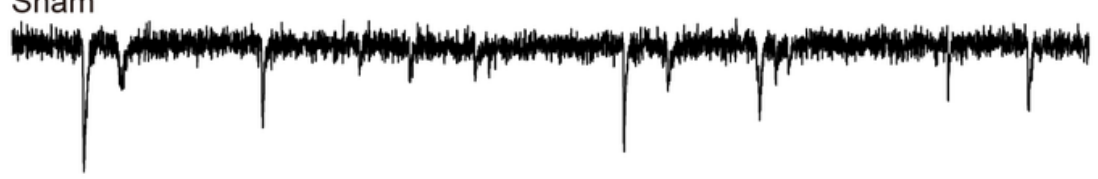

6-OHDA

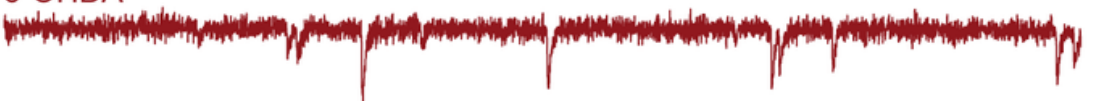

$6-\mathrm{OHDA}+\mathrm{EA}$

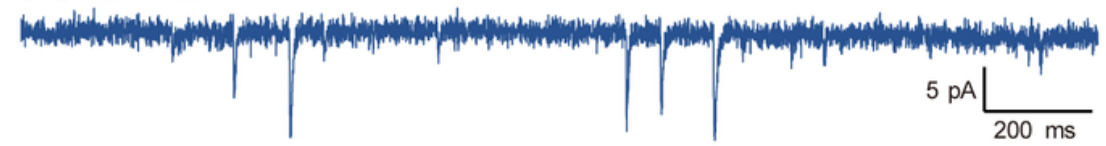

D

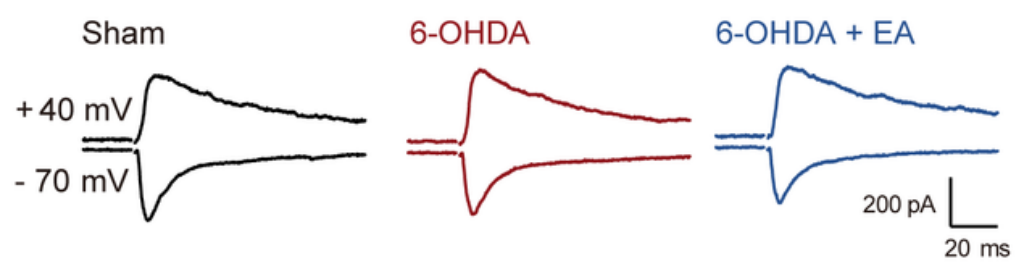

B

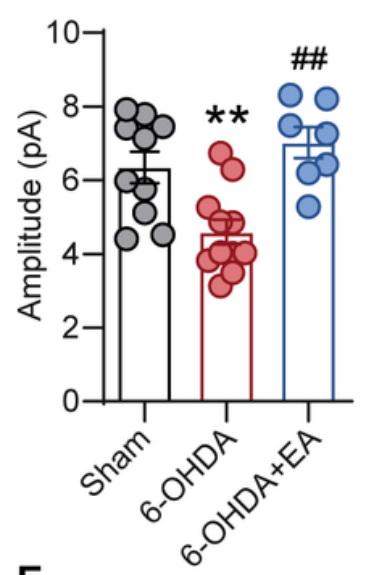

E

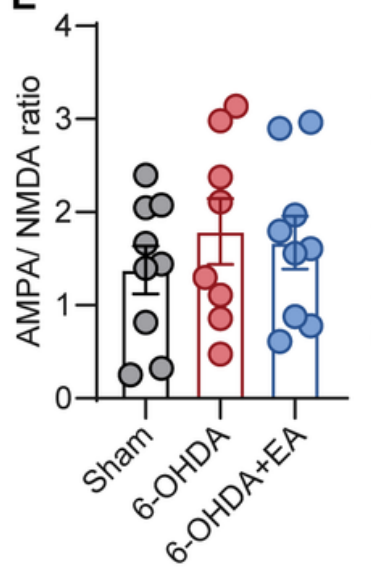

C

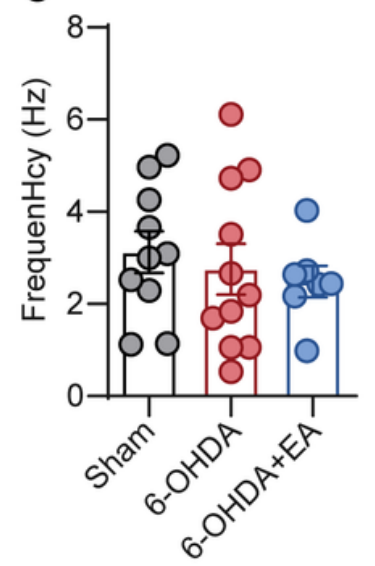

$\mathbf{F}$

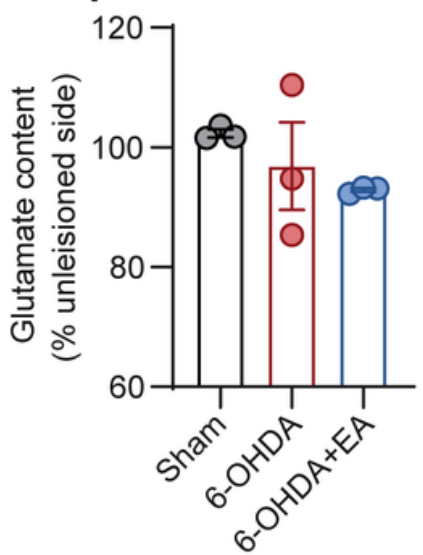

\section{Figure 5}

EA treatment modulated postsynaptic AMPA- and NMDA- receptor mediated synaptic responses in the striatum of partial-lesioned mice. a Representative traces of AMPA-mediated mEPSCs of MSNs in the presence of TTX $(0.5 \mu \mathrm{M})$ and PTX $(100 \mu \mathrm{M})$ from acute striatal brain slices in sham, 6-OHDA and 6OHDA + EA group. b, c Cumulative data of mEPSCs amplitude (B) and frequency (C) from striatal MSNs. $\mathrm{N}=10$ cells from 3 sham mice, 7 cells from $46-$ OHDA mice and 10 cells from $46-$ OHDA + EA mice. $d$ Example traces of AMPA and NMDA EPSCs evoked by extracellular stimulating electrode placed on corpus callosum, while cells were held at -70 and $+40 \mathrm{mV}$, respectively. e The bar histogram analyzing the AMPA/NMDA ratio, while AMPA evoked EPSCs were measured as the peak amplitude, NMDA evoked EPSCs were measured as a $10 \mathrm{~ms}$ window beginning $50 \mathrm{~ms}$ after the stimulus artifact. $\mathrm{N}=9$ cells from 4 sham mice, 8 cells from 4 6-OHDA mice and 9 cells from 4 6-OHDA + EA mice. f Relative content of glutamate in the ipsilateral striatum compared to the unlesioned side, $\mathrm{N}=3$ per group. Data are expressed as means \pm SEM. One-way ANOVA analysis followed by Tukey post-test, except that two-way ANOVA 
analysis followed by Tukey post-test for input-output curve. ${ }^{\star \star P} \mathrm{P}<0.01$ vs. sham group; \#\#P $<0.01$ vs. 6 OHDA group.

A

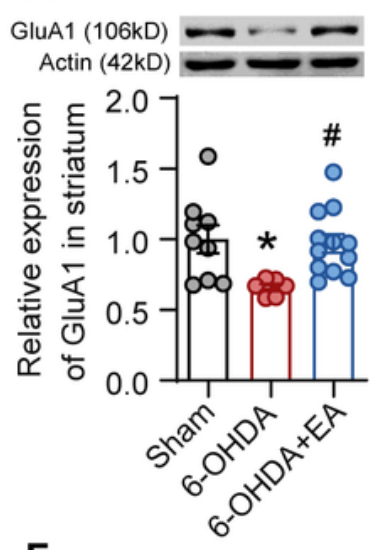

$\mathbf{F}$

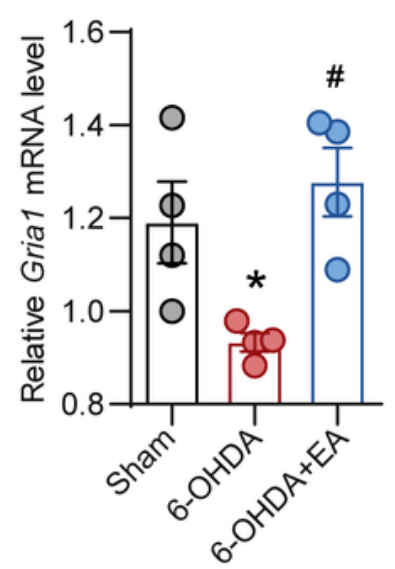

K

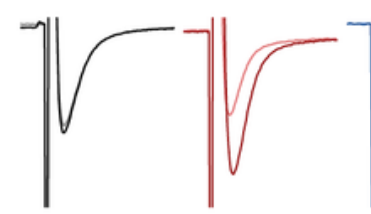

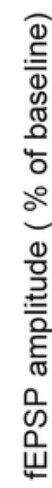

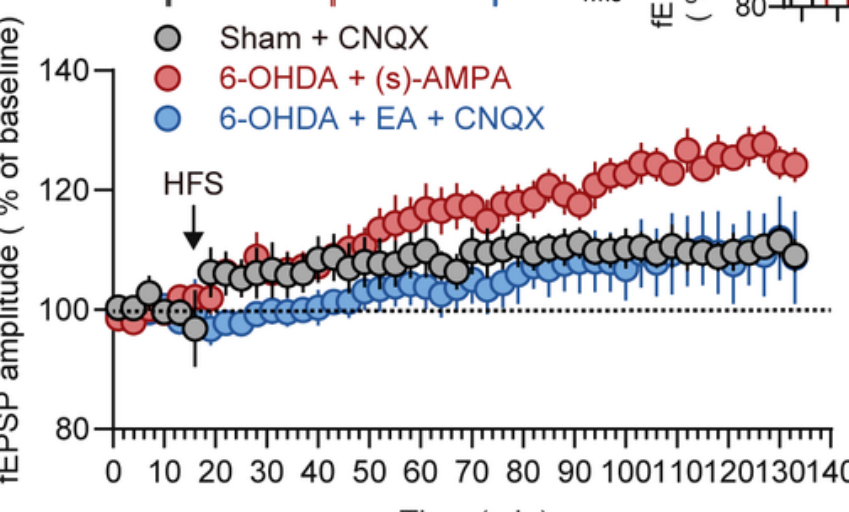

Time (min)

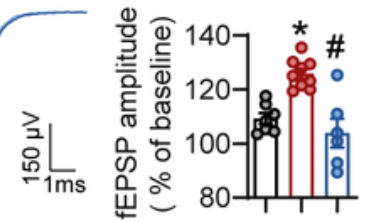

C
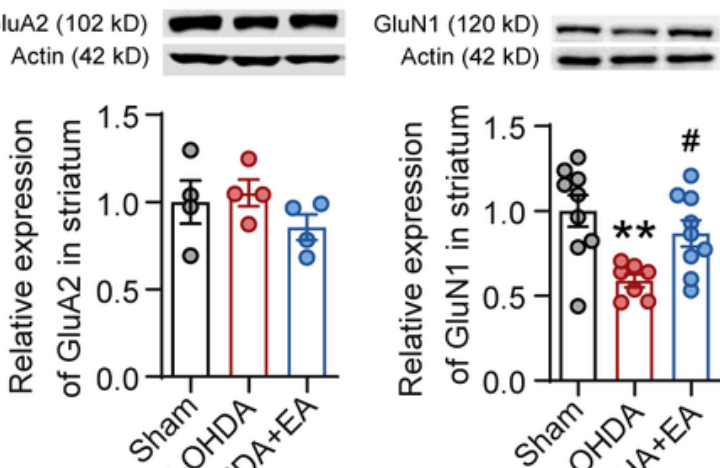

G

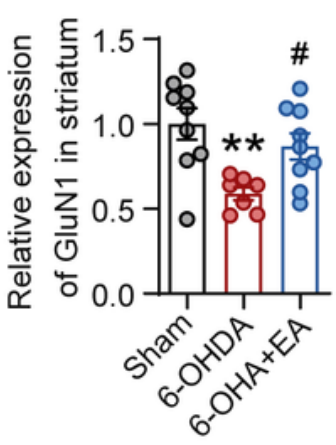

H
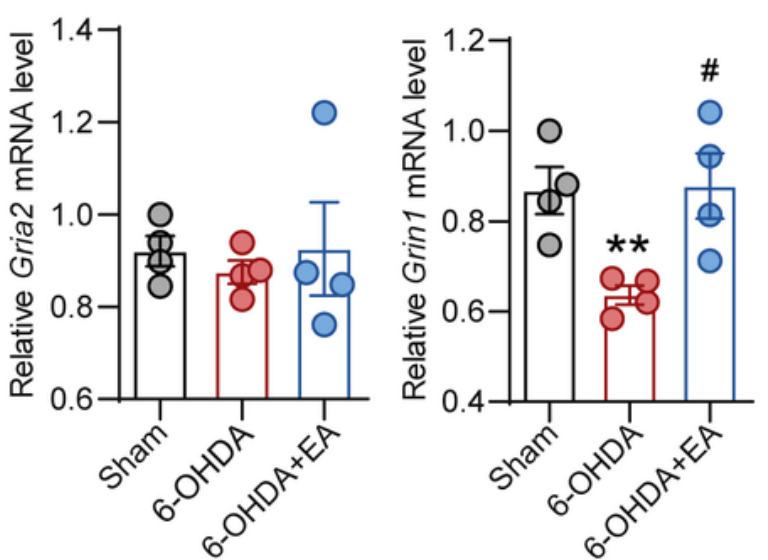

E

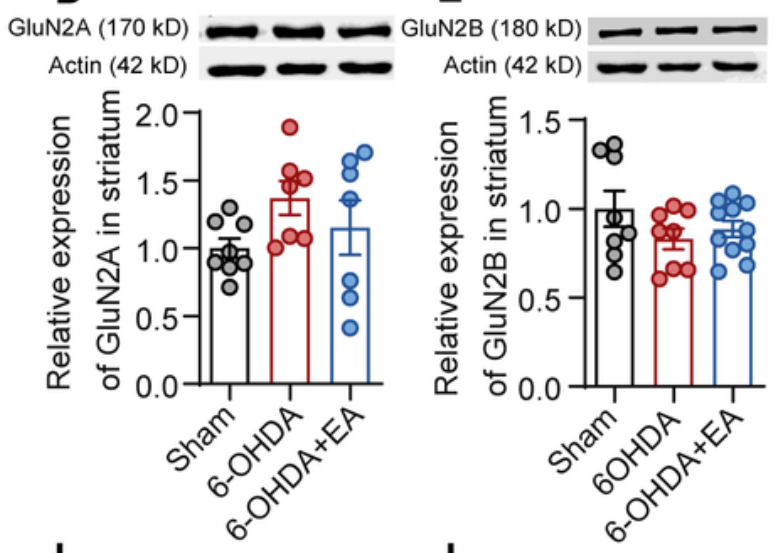

J
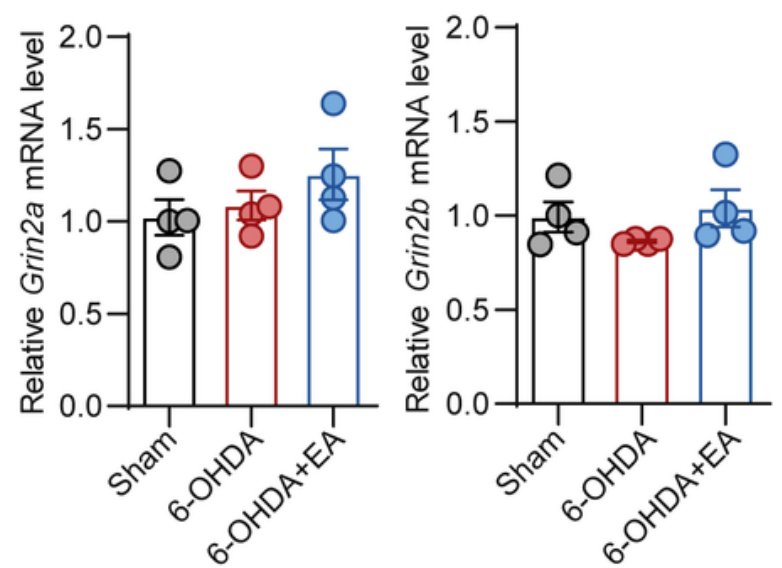

L
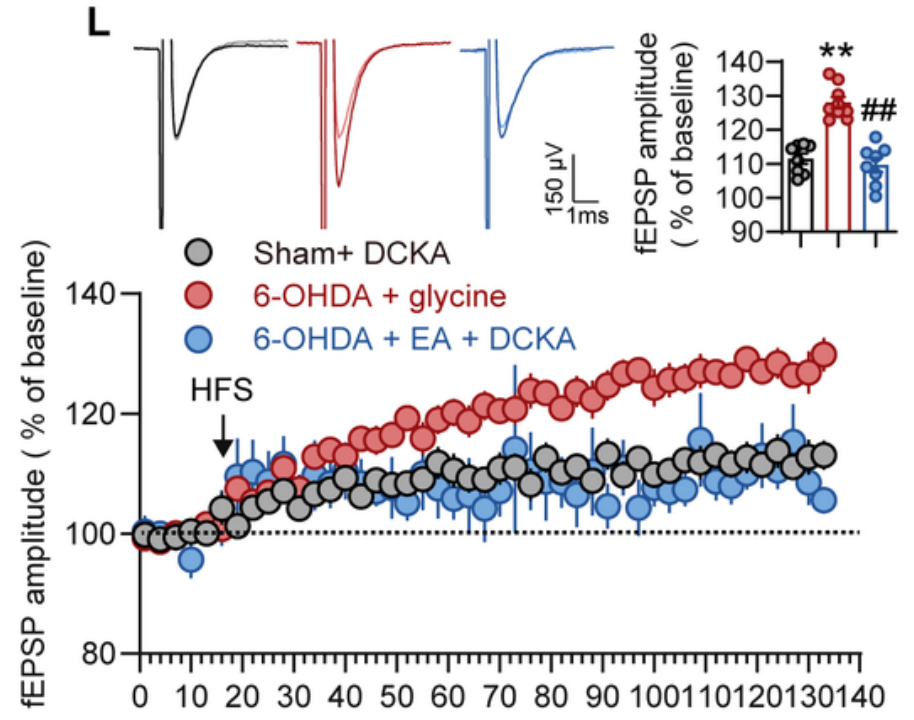

Time (min)

\section{Figure 6}

AMPA and NMDA antagonist inhibited the effects of EA on striatal LTP in partial-lesioned mice. a-e Top, western blot bands showed the protein expression of AMPA subunits (GluA1 and GluA2) and NMDA subunits (GluN1, GluN2A and GluN2B). $\beta$-Actin was the loading control and each lane was normalized to 
sham levels. Bottom, quantification of AMPA and NMDA subunits expressions., $N=4-12$ per group. $\mathrm{f}-\mathrm{j}$ Quantification of AMPA subunits encoded mRNA (Gria1 and Gria2) and NMDA subunits encoded mRNA (Grin1, Grin2a and Grin2b) levels based on qRT-PCR data, $N=4$ per group. $k$ Top, representative traces of sham + CNQX, 6-OHDA + (s)-AMPA and 6-OHDA + EA + CNQX slices extracted within 0-15 min (light traces) and the last 10 min (dark traces). Bottom, cumulative data of LTP induced by HFS in the dorsolateral striatum. Insert, bar graph representing the average fEPSPs amplitude of the last $10 \mathrm{~min}$ after LTP induction. $2 \mu \mathrm{M}$ CNQX or $10 \mu \mathrm{M}$ (s)-AMPA were perfused in ACSF during the whole recording experiment. $\mathrm{N}=7$ slices from 3 sham mice, 9 slices from 4 6-OHDA mice and 6 slices from 36 6-OHDA + EA mice. I Top, representative traces of sham + DCKA, 6-OHDA + glycine and 6-OHDA + EA + DCKA slices extracted within 0-15 min and the last $10 \mathrm{~min}$. Bottom, cumulative data of LTP induced by HFS in the dorsolateral striatum. Insert, bar graph representing the average fEPSPs amplitude of the last $10 \mathrm{~min}$ after LTP induction. $\mathrm{N}=8$ slices from 3 sham mice, 9 slices from 3 6-OHDA mice and 8 slices from 36 $\mathrm{OHDA}+\mathrm{EA}$ mice. Data are expressed as means $\pm \mathrm{SEM}$. ${ }^{*} \mathrm{P}<0.05$, ${ }^{*} \mathrm{P}<0.01$ vs. sham group; $\# \mathrm{P}<0.05$, $\# \# P<0.01$ vs. 6-OHDA group, one-way ANOVA analysis followed by Tukey post-test.

\section{Supplementary Files}

This is a list of supplementary files associated with this preprint. Click to download.

- figs520200823.tif

- figs520200823.tif

- figs420200816.tif

- figs420200816.tif

- figs320200823.tif

- figs320200823.tif

- figs220200823.tif

- figs220200823.tif

- figs120200823.tif

- figs120200823.tif 